\title{
Article \\ Control of a Variable-Impedance Fault Current Limiter to Assist Low-Voltage Ride-Through of Doubly Fed Induction Generators
}

\author{
Jiejie Huang ${ }^{1}{ }^{\oplus}$, Shun Sang ${ }^{1,2} \mathbb{D}$, Lei Zhang ${ }^{1, *} \mathbb{\infty}$, Xiaocen Xue ${ }^{1, *}$ and Tingting Sun ${ }^{3}$ \\ 1 School of Electrical Engineering, Nantong University, Nantong 226019, China; huangjiejie@ntu.edu.cn (J.H.); \\ chrissang@yeah.net (S.S.) \\ 2 Key Laboratory of Control of Power Transmission and Conversion, Shanghai Jiao Tong University, \\ Shanghai 200240, China \\ 3 School of Electrical and Energy Engineering, Nantong Institute of Technology, Nantong 226002, China; \\ suntingting@mail.hfut.edu.cn \\ * Correspondence: nttzzl@ntu.edu.cn (L.Z.); xiaocenxue@163.com (X.X.)
}

Citation: Huang, J.; Sang, S.; Zhang, L.; Xue, X.; Sun, T. Control of a Variable-Impedance Fault Current Limiter to Assist Low-Voltage Ride-Through of Doubly Fed Induction Generators. Electronics 2021, 10, 2364. https://doi.org/ 10.3390/electronics10192364

Academic Editor: Fabian Khateb

Received: 7 September 2021

Accepted: 27 September 2021

Published: 28 September 2021

Publisher's Note: MDPI stays neutral with regard to jurisdictional claims in published maps and institutional affiliations.

Copyright: (c) 2021 by the authors. Licensee MDPI, Basel, Switzerland. This article is an open access article distributed under the terms and conditions of the Creative Commons Attribution (CC BY) license (https:// creativecommons.org/licenses/by/ $4.0 /)$.

\begin{abstract}
A fault current limiter (FCL) may be applied to assist the low-voltage ride-through (LVRT) of a doubly fed induction generator (DFIG). FCLs with fixed impedance, lack the flexibility to adjust their impedance to adapt to different LVRT scenarios. The direct switch-in and -out of the fixedimpedance FCL yields transient electromagnetic oscillations in the DFIG, which need to be addressed. In this paper, a variable-impedance FCL is implemented at the stator side of the DFIG to assist its LVRT, and a novel methodology is proposed to control the impedance of the FCL, with which the stator current oscillation is effectively constrained and the smooth switch-out of the FCL is realized to avoid continued active power consumption of the FCL and to restore the DFIG to its pre-fault working condition. Analysis of the LVRT transient is carried out, which lays the foundation for the control methodology to determine the impedance of the FCL based on calculation of the optimization goal. The feasibility and effectiveness of the control to the variable-impedance FCL are verified by the numerical analysis results, which compare the LVRT simulation results with the application of the fixed-impedance and the variable-impedance FCLs.
\end{abstract}

Keywords: low-voltage ride-through; variable-impedance fault current limiter; doubly fed induction generator; analytical analysis; current oscillation suppression; active power consumption

\section{Introduction}

Due to their the merits, which include variable-speed constant-frequency operation capability and low investment requirement, DFIGs have become one of the most widely applied types of wind turbine generators (WTGs) [1-3]. Stability issues with the integration of WTGs have become a hot research topic [4] and are becoming increasingly complicated with the development of the offshore wind farms. A comprehensive review on the power transmission technology involved in offshore wind farms was carried out in [5], where the capabilities of WTGs to realize LVRT and support the system frequency through the active power control were introduced in detail. The LVRT capability is a major concern in the fault scenarios of wind power systems [6,7]. To assist the LVRT of the DFIG, both software control schemes and hardware protection schemes have been developed [8]. The former usually involves improvement to the converter control of the DFIG, e.g., adjusting the power/current control references according to the LVRT scenario [9], and eliminating the impact of stator flux oscillation yielded by the voltage dip on the converter control through feed-forward compensation $[10,11]$. The latter assists the LVRT with the application of hardware protections, e.g., the crowbar [12,13], FCL [14,15], dynamic voltage restorer (DVR) [16,17], STATCOM [18], and so on. Software control schemes do not require extra investment in protection equipment; however, their ability to deal with severe voltage dips 
of large capacity WTGs is constrained. In this case, hardware protections are still needed to guarantee a successful LVRT.

Hardware protections can be categorized into two kinds depending on how they operate to assist the LVRT. The first kind aims to relieve the voltage drop sensed by the WTGs. For example, the DVR attempts to compensate for the voltage drop and the STATCOM tries to support the voltage at the point of coupling during the LVRT. These usually require large capacity, and thus require comparatively high investment. The second kind aims to limit the transient electromagnetic oscillations in the WTGs yielded by the voltage drop to achieve the successful LVRT. A typical example of this kind is the FCL, which has been extensively applied in the LVRTs of DFIGs. Similarly, the crowbar works as a resistive-type FCL placed at the rotor side after it blocks the rotor-side converter (RSC) of the DFIG during the LVRT [19].

As a hardware protection scheme, the FCL is easy to implement, and has a fast response speed. Different types of the FCLs may be used for LVRT, including the resistive type [20], inductive type [21], and hybrid (impedance) type FCLs [22]. Superconducting material may be applied to the FCL to improve its effect. In [23], application of resistiveand inductive-type superconducting FCLs to assist the LVRT of WTGs was analyzed. All types of FCLs are capable of reducing the fault current. The advantage of resistive-type FCLs lies in their ability to damp the electromagnetic oscillations. The inductive type FCL is more capable of supporting the terminal voltage with the reactive current output flowing through the inductance, which is required by the grid code [24]. In DFIGs, the FCL may be implemented at the stator side [25] or the rotor side [9]. Implementing FCLs at the stator side helps to damp the oscillations in the stator circuit. The oscillations in the rotor circuit yielded by coupling between the stator and rotor circuits are also relieved. An FCL placed at the stator side achieves a superior control effect [26].

Considering the flexibility of the FCL protection under different LVRT scenarios, FCLs with controllable resistance have been a popular choice over traditional fixed-impedance FCLs. A variable-impedance FCL usually consists of an impedance path that determines the maximum impedance of the FCL, and a power electronics switch that controls the equivalent impedance of the FCL by adjusting the duty ratio of the switching signal [27]. With this, instead of applying the full impedance of the FCL during the LVRT, a variable impedance may be provided to improve the LVRT performance.

There are, however, some issues to address in the control of variable-impedance FCLs. A typical control target for a variable-impedance FCL is to compensate for the stator voltage dip. The impedance of the FCL is controlled through a PI control link. The input of the PI control is the difference between the stator voltage and its reference [28]. This scheme is able to realize stator voltage compensation for different voltage dip depths resulting from various fault conditions. However, this scheme still has some drawbacks to overcome. Firstly, the stator voltage does not need to be compensated at a high level during the LVRT. The damage caused by low voltage to the DFIG is mostly due to the intense oscillation of the transient stator current, which can be damped with the temporary switch-in of the FCL. Moreover, with the stator voltage compensated at a high level, the voltage at the DFIG terminal is not improved, apart from the voltage recovery due to the reactive current support. On the contrary, the FCL itself may consume large amounts of active power during the switch-in period, which may lead to temperature rise in the FCL. This thermal effect needs to be taken into consideration to ensure operational security [29]. Also, the consumed active power constrains the capability of the DFIG to provide active power support for frequency stability during the LVRT [30], which has recently attracted attention from researchers. With all this in mind, a control strategy to switch out the FCL needs to be developed, which utilizes the advantage of the variable-impedance FCL over fixed-impedance FCLs. The direct switch-out of the fixed-impedance FCL instantly causes another abrupt voltage change, once again yielding the stator current oscillations. To switch out the variable impedance FCL, a ramp function has been applied. In [31], the ramp function is adopted to control the resistance of the resistive-type FCL in order to 
switch it out. However, the selection of the coefficient in the ramp function has not been studied, which will affect the LVRT performance. To control the variable-impedance FCL for the desired LVRT effect, a control strategy needs to be developed on the basis of the LVRT analysis.

In this paper, the control of a variable-impedance FCL placed at the stator side of a DFIG is studied to improve LVRT performance. First, the control scheme to RSC of the DFIG considering the switch-in of the FCL is developed. Then, analysis on the LVRT transient is carried out, based on which an index that considers both the ability to suppress current oscillation and the active power consumption of the FCL is calculated. During the LVRT process, the impedance of the FCL is controlled to obtain the optimal LVRT index. Numerical analysis results show that, with this control scheme, the variable impedance FCL is able to suppress the electromagnetic oscillations during the LVRT. Also, the impedance is gradually reduced with constrained oscillations during the switch-out process. Simulation results show that the variable-impedance FCL has advantages over the fixed-impedance FCL in the following aspects: superior LVRT performance, flexibility in control target setting, and adaptivity to different voltage dips. Improvements over the ramp function to control the impedance of the variable-impedance FCL are also verified based on comparison of LVRT performances.

This paper is organized as follows. Section 2 introduces the implementation of the variable-impedance FCL to assist the LVRT of the DFIG, and how the RSC control is adjusted in coordination with the switch-in of the FCL. Section 3 describes the analysis on the LVRT transient of the DFIG with the application of the variable-impedance FCL and optimizes the control to the impedance of the FCL. The effectiveness of the proposed control scheme to improve the LVRT performance with the variable-impedance FCL is verified by the numerical analysis results in Section 4 . Conclusions are given in Section 5.

\section{LVRT of DFIG with Variable-Impedance FCL}

\subsection{Control Principal of Bridge-Type FCL for LVRT of DFIG}

A single-machine infinite-bus (SMIB) model of DFIG is illustrated in Figure 1, where $V$ and $I$ are sinusoidal voltage and sinusoidal current, subscripts s, r, GSC, and PCC denote the stator, rotor, grid-side converter, and point of common coupling. To assist the LVRT of the DFIG, the FCL is placed on the stator side of the DFIG.

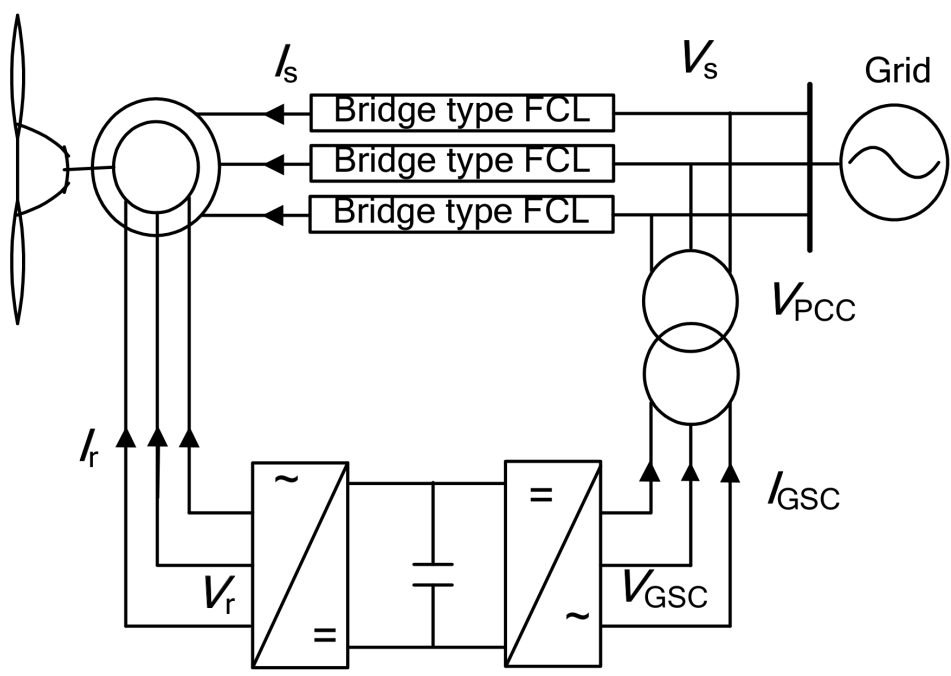

Figure 1. SMIB model of DFIG with FCL placed on the stator side.

A bridge-type FCL with variable impedance is applied to the LVRT of the DFIG. Its configuration is shown in Figure 2. The bridge-type FCL contains a bridge path and a shunt path. Four diodes D1, D2, D3, and D4 form the bridge configuration. A DC reactor with a small value $L_{\mathrm{dc}}$ is connected in series with the IGBT switch, and the inherited resistance of 
the DC reactor is represented by $R_{\mathrm{dc}}$. The free-wheeling diode D5 is equipped to the dc reactor to guarantee secure operation. The resistor $R_{\mathrm{FCL}}$ and inductor $L_{\mathrm{FCL}}$ form a shunt path, which provides impedance to limit the fault current when the IGBT switches out to drive the flowing current to the shunt path. When a fault is detected, the FCL is switched in by shutting down the IGBT path. The impedance of the FCL is controlled by adjusting the duty ratio of the control signal applied to the IGBT switch. The equivalent impedance of the FCL is given by Equation (1), where $d$ is the duty ratio of the switch signal, $\omega_{0}$ is the synchronous rotating speed, and $Z_{\mathrm{FCL}}^{\mathrm{eq}}$ is the equivalent impedance of the FCL.

$$
Z_{\mathrm{FCL}}^{\mathrm{eq}}=d\left(R_{\mathrm{FCL}}+\mathrm{j} \omega_{0} L_{\mathrm{FCL}}\right)
$$

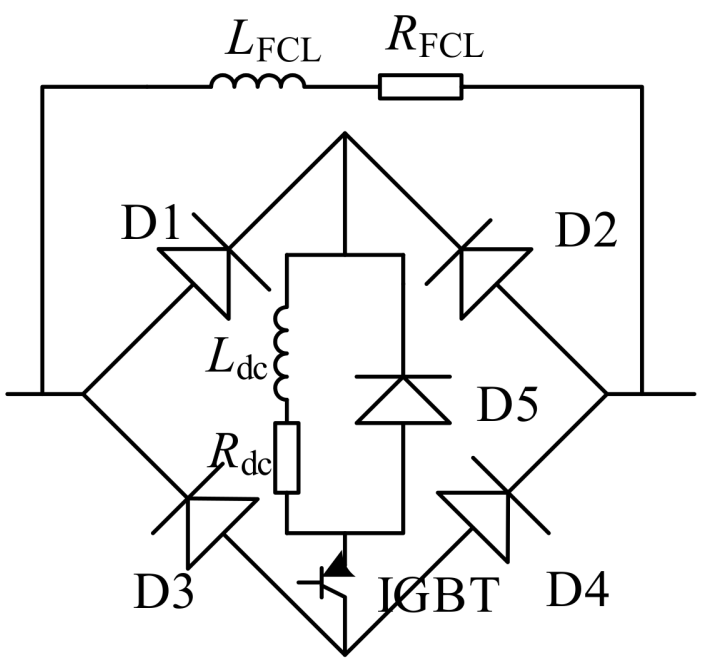

Figure 2. Configuration of bridge-type fault current limiter.

When voltage dips at the generator terminal are detected, the variable-impedance FCL is switched in to suppress the fault current oscillation. The resistance of the FCL helps to increase damping of the amplitude of current oscillation. Once the oscillations have been sufficiently damped, the continued switch-in of the FCL consumes large quantities of active power. This constrains the active power output capability of the DFIG during the LVRT, resulting in the degraded frequency stability of the wind power system.

After the clearance of the fault, the voltage recovery process also yields intense electromagnetic oscillations, which requires the FCL to be switched in to suppress the current oscillations. After damping of the oscillations is achieved, the FCL needs to be switched out to avoid high stator voltage compared to normal operation value. Abrupt switch-out of the FCL needs to be avoided as it results in abrupt stator voltage loss, leading to the undesired voltage dip ride-through transient. With the variable-impedance FCL, the FCL is switched out in such a way that the impedance of the FCL is gradually decreased to relieve the transient oscillations.

\subsection{Rotor-Side Converter Control Coordinated with Switch-In of the FCL}

When the FCL is switched in at the stator side, the configuration of the DFIG changes. The control scheme to the RSC for the active and reactive power control of the DFIG needs to be adjusted accordingly. The adjustment to the RSC control is derived below.

The flux and voltage equations of the DFIG are given by

$$
\begin{gathered}
\boldsymbol{V}_{\mathrm{s}}=R_{\mathrm{s}} \boldsymbol{I}_{\mathrm{s}}+\mathrm{j} \omega_{0} \boldsymbol{\psi}_{\mathrm{s}}+\mathrm{p} \boldsymbol{\psi}_{\mathrm{s}} \\
V_{\mathrm{r}}=R_{\mathrm{r}} \boldsymbol{I}_{\mathrm{r}}+\mathrm{j} s \omega_{0} \boldsymbol{\psi}_{\mathrm{r}}+\mathrm{p} \boldsymbol{\psi}_{\mathrm{r}} \\
\boldsymbol{\psi}_{\mathrm{s}}=L_{\mathrm{s}} \boldsymbol{I}_{\mathrm{s}}+L_{\mathrm{m}} \boldsymbol{I}_{\mathrm{r}}
\end{gathered}
$$




$$
\psi_{\mathrm{r}}=L_{\mathrm{r}} \boldsymbol{I}_{\mathrm{r}}+L_{\mathrm{m}} \boldsymbol{I}_{\mathrm{s}}
$$

where $\psi$ is the flux, $L_{\mathrm{m}}$ is the mutual inductance, $s$ is the slip, $\mathrm{p}$ is the differential operator that calculates the derivative with respect to time, e.g., $\mathrm{p} \psi_{\mathrm{s}}=\mathrm{d} \psi_{\mathrm{s}} / \mathrm{d} t$, and $\omega_{0}$ is the synchronous rotating speed.

Equations (2)-(5) are the vector model of the DFIG, which is widely applied in the LVRT analysis, as can be referred in [10].

For the vector control with direct-axis (d-axis) voltage orientation, i.e. $V_{\mathrm{sd}}=V_{\mathrm{s}}$, $V_{\mathrm{sq}}=0$, decoupled control of the active power and reactive power of the stator is realized by regulating the $\mathrm{d}$-axis stator current and the quadrature-axis (q-axis) stator current respectively. With the constant stator voltage, steady-state stator flux is obtained. The corresponding rotor current reference is calculated based on Equation (4).

As for the RSC control, the rotor current is regulated by adjusting the rotor voltage. Combing Equations (2)-(5), the rotor voltage is written as

$$
\left\{\begin{aligned}
V_{\mathrm{r}} & =\underbrace{R_{\mathrm{r}} \boldsymbol{I}_{\mathrm{r}}+L_{\mathrm{r}}^{\prime} \mathrm{p} I_{\mathrm{r}}}_{\text {Rotor current related terms }}+\underbrace{\mathrm{j} s \omega_{0}\left(L_{\mathrm{m}} I_{\mathrm{s}}+L_{\mathrm{r}} \boldsymbol{I}_{\mathrm{r}}\right)}_{\text {Cross-coupling terms }}+\underbrace{\underbrace{L_{\mathrm{s}}}_{L_{\mathrm{m}}} \mathrm{p} \psi_{\mathrm{s}}}_{\text {Stator flux related term }} \\
L_{\mathrm{r}}^{\prime} & =L_{\mathrm{r}}-\frac{L_{\mathrm{m}}^{2}}{L_{\mathrm{s}}}
\end{aligned}\right.
$$

The PI control to regulate the rotor current by adjusting the rotor voltage is designed based on the above rotor voltage equation. As for the rotor current related terms, they are replaced by the PI control link. The input of the PI control is the difference between the rotor current and its reference. The feed-forward terms are added to compensate for the cross-coupling terms and the stator flux-related terms. The change rate of the stator flux may be obtained based on the stator voltage equation (Equation (2)). However, when the FCL placed at the stator side is switched-in for the LVRT, the stator voltage equation is rewritten as

$$
V_{\mathrm{s}}=\left(R_{\mathrm{s}}+d R_{\mathrm{FCL}}+d \mathrm{j} \omega_{0} L_{\mathrm{FCL}}\right) \boldsymbol{I}_{\mathrm{s}}+\mathrm{j} \omega_{0} \boldsymbol{\psi}_{\mathrm{s}}+\mathrm{p} \boldsymbol{\psi}_{\mathrm{s}}
$$

Combining Equations (6) and (7), the d-axis and q-axis PI rotor current control of the RSC, considering the switch-in of the FCL, is given by

$$
\begin{aligned}
V_{\mathrm{rd}} & =k_{\mathrm{p}}\left(I_{\mathrm{rd}}^{\mathrm{ref}}-I_{\mathrm{rd}}\right)+k_{\mathrm{i}} \int\left(I_{\mathrm{rd}}^{\mathrm{ref}}-I_{\mathrm{rd}}\right) \mathrm{dt}-s \omega_{0}\left(L_{\mathrm{m}} I_{\mathrm{sq}}+L_{\mathrm{r}} I_{\mathrm{rq}}\right) \\
& +\frac{L_{\mathrm{m}}}{L_{\mathrm{s}}} V_{\mathrm{sd}}-\frac{L_{\mathrm{m}}}{L_{\mathrm{s}}}\left(R_{\mathrm{s}}+d R_{\mathrm{FCL}}\right) I_{\mathrm{sd}}+\frac{L_{\mathrm{m}}}{L_{\mathrm{s}}} d \omega_{0} L_{\mathrm{FCL}} I_{\mathrm{sq}}+\frac{L_{\mathrm{m}}}{L_{\mathrm{s}}} \omega_{0} \psi_{\mathrm{sq}} \\
V_{\mathrm{rq}} & =k_{\mathrm{p}}\left(I_{\mathrm{rq}}^{\mathrm{ref}}-I_{\mathrm{rq}}\right)+k_{\mathrm{i}} \int\left(I_{\mathrm{rq}}^{\mathrm{ref}}-I_{\mathrm{rq}}\right) \mathrm{dt}+s \omega_{0}\left(L_{\mathrm{m}} I_{\mathrm{sd}}+L_{\mathrm{r}} I_{\mathrm{rd}}\right) \\
& +\frac{L_{\mathrm{m}}}{L_{\mathrm{s}}} V_{\mathrm{sq}}-\frac{L_{\mathrm{m}}}{L_{\mathrm{s}}}\left(R_{\mathrm{s}}+d R_{\mathrm{FCL}}\right) I_{\mathrm{sq}}-\frac{L_{\mathrm{m}}}{L_{\mathrm{s}}} d \omega_{0} L_{\mathrm{FCL}} I_{\mathrm{sd}}+\frac{L_{\mathrm{m}}}{L_{\mathrm{s}}} \omega_{0} \psi_{\mathrm{sd}}
\end{aligned}
$$

where $k_{\mathrm{p}}$ and $k_{\mathrm{i}}$ are the proportional and integral gains of the PI control, respectively, and superscript ref denotes the reference value.

The difference between the rotor current and its reference goes through the PI control link to adjust the rotor voltage to obtain the desired rotor current output. The integral link outputs the integral of the rotor current difference as a part of the rotor voltage output.

The corresponding diagram of RSC control is shown in Figure 3. The rotor current control is realized in the $\mathrm{d}-\mathrm{q}$ coordinate, as show in Figure 3 where the direct axis and the quadrature axis rotor current references are directly prescribed. To implement this control scheme, $a, b$, and $c$ phase quantities are firstly transformed to an $\alpha-\beta$ coordinate through Clark transformation and then transformed to a $\mathrm{d}-\mathrm{q}$ coordinate through Park transformation. Through the above-mentioned transformation process, the $\mathrm{d}-\mathrm{q}$ axis rotor current reference may be transformed back to phase $a, b$, and $c$ curves. 

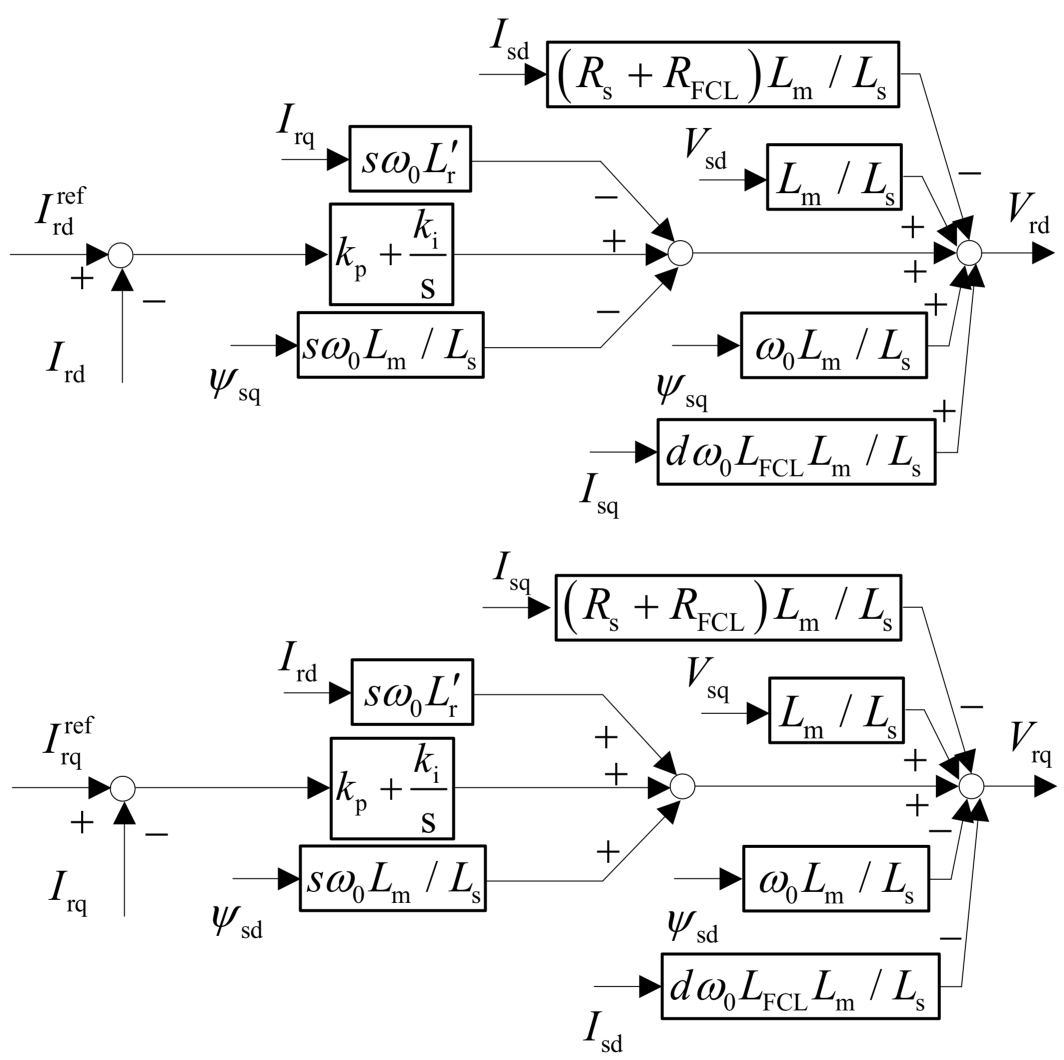

Figure 3. Diagram of RSC control considering switch-in of the FCL.

\section{Control of the Impedance of the FCL Based on LVRT Analysis}

\subsection{Analysis of LVRT}

To analyze the impact of FCL impedance on the LVRT of DFIGs, analysis of the LVRT transient is carried out.

The dynamic the rotor current may be obtained by solving the second-order differential equation combining the rotor voltage equation (Equation (6)) and the rotor voltage control equation (Equations (8) and (9)), as given by

$$
\mathrm{p}^{2} \boldsymbol{I}_{\mathrm{r}}+\frac{R_{\mathrm{r}}+k_{\mathrm{p}}}{L_{\mathrm{r}}^{\prime}} \mathrm{p} \boldsymbol{I}_{\mathrm{r}}+\frac{k_{\mathrm{i}}}{L_{\mathrm{r}}^{\prime}} \boldsymbol{I}_{\mathrm{r}}=\frac{k_{\mathrm{i}}}{L_{\mathrm{r}}^{\prime}} \boldsymbol{I}_{\mathrm{r}}^{\mathrm{ref}}
$$

Solving Equation (10), the analytical expression of rotor current is derived as Equation (11):

$$
\left\{\begin{array}{l}
\boldsymbol{I}_{\mathrm{r}}=\boldsymbol{I}_{\mathrm{r}}^{\mathrm{ref}}+\boldsymbol{c}_{1} \mathrm{e}^{r_{1} t}+\boldsymbol{c}_{2} \mathrm{e}^{r_{2} t} \\
r_{1,2}=\left(-\left(R_{\mathrm{r}}+k_{\mathrm{p}}\right) \pm \sqrt{\left(R_{\mathrm{r}}+k_{\mathrm{p}}\right)^{2}-4 k_{\mathrm{i}} L_{\mathrm{r}}^{\prime}}\right) /\left(2 L_{\mathrm{r}}^{\prime}\right) \\
\boldsymbol{c}_{1}=\left(\mathrm{p} \boldsymbol{I}_{\mathrm{r}}^{\text {ini }}-r_{2}\left(\boldsymbol{I}_{\mathrm{r}}^{\text {ini }}-\boldsymbol{I}_{\mathrm{r}}^{\text {ref }}\right)\right) /\left(r_{1}-r_{2}\right) \\
\boldsymbol{c}_{2}=\left(\mathrm{p} \boldsymbol{I}_{\mathrm{r}}^{\text {ini }}-r_{1}\left(\boldsymbol{I}_{\mathrm{r}}^{\text {ini }}-\boldsymbol{I}_{\mathrm{r}}^{\text {ref }}\right)\right) /\left(r_{2}-r_{1}\right) \\
\mathrm{p} \boldsymbol{I}_{\mathrm{r}}^{\text {ini }}=k_{\mathrm{p}}\left(\boldsymbol{I}_{\mathrm{r}}^{\text {ref }}-\boldsymbol{I}_{\mathrm{r}}^{\text {ini }}\right) / L_{\mathrm{r}}^{\prime}
\end{array}\right.
$$

where superscript ini denotes the initial value.

As mentioned before, the impact of stator flux oscillation on the rotor current control is eliminated by the feed-forward compensation. In this case, the rotor current can be regarded as an external condition to analyze the transient stator flux and current. The main factor to consider is the voltage dip depth. With the switch-in of the FCL, its impact on the response of the stator winding to the voltage dip needs to be considered. To obtain the analytical solution to the stator flux and current, the procedure is illustrated in Figure 4. 


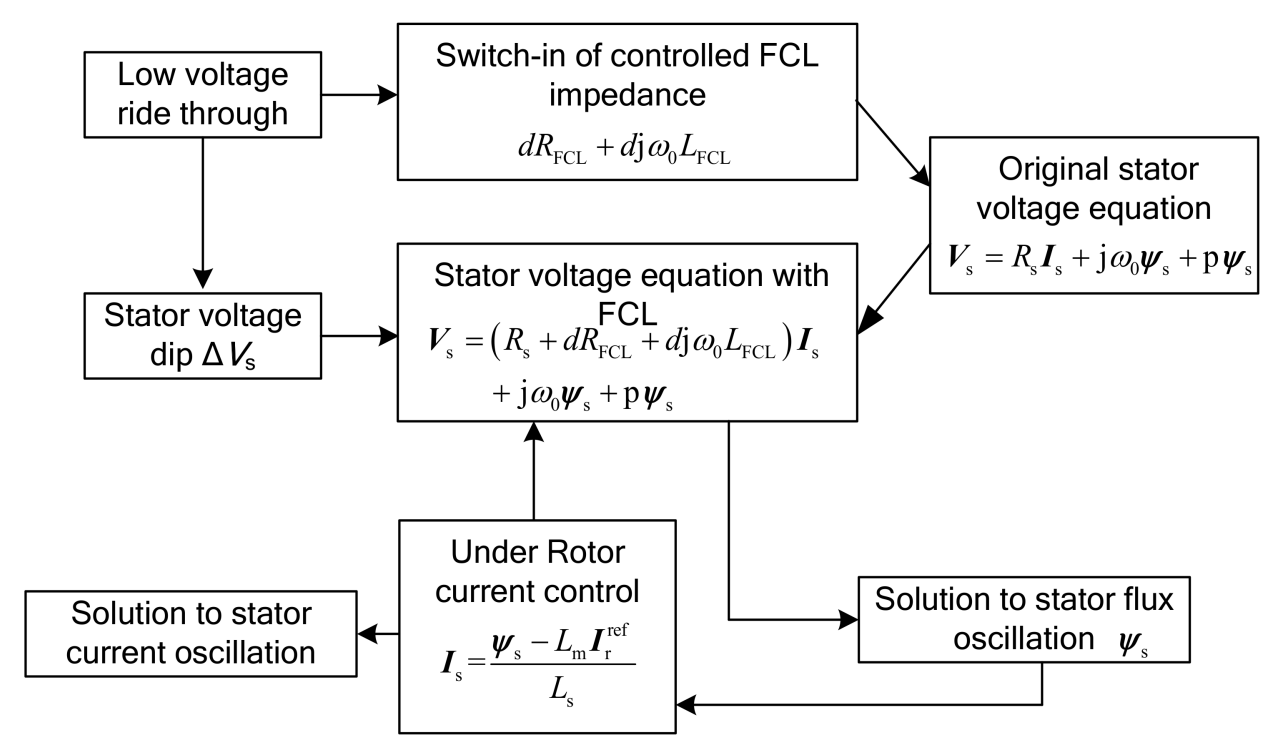

Figure 4. Procedure to obtain the analytical solution of transient stator flux and current.

Given the fast response of the inner-loop current control, the rotor current is considered to instantly reach the reference. Based on this assumption, the stator flux and current are derived based on the differential equation of the stator voltage (Equation (7)).

Assuming the rotor current is controlled to its reference, Equation (7) is rewritten as a first-order differential equation of the stator flux, as given by Equation (12):

$$
\boldsymbol{V}_{\mathrm{s}}=\left(R_{\mathrm{s}}+d R_{\mathrm{FCL}}+d \mathrm{j} \omega_{0} L_{\mathrm{FCL}}\right) \frac{\boldsymbol{\psi}_{\mathrm{s}}-L_{\mathrm{m}} \boldsymbol{I}_{\mathrm{r}}^{\mathrm{ref}}}{L_{\mathrm{s}}}+\mathrm{j} \omega_{0} \boldsymbol{\psi}_{\mathrm{s}}+\mathrm{p} \psi_{\mathrm{s}}
$$

Solving Equation (12), the analytical expressions of the stator flux and the stator current are given by Equation (13):

$$
\left\{\begin{array}{l}
\psi_{\mathrm{s}}=\psi_{\mathrm{s}}^{\infty}+\left(\boldsymbol{\psi}_{\mathrm{s}}^{\mathrm{ini}}-\psi_{\mathrm{s}}^{\infty}\right) \mathrm{e}^{-\tau t-\mathrm{j} \omega_{0}\left(\frac{d L_{\mathrm{FCL}}}{L_{\mathrm{S}}}+1\right)} \\
\boldsymbol{\psi}_{\mathrm{s}}^{\infty}=\frac{k V_{\mathrm{s}}+L_{\mathrm{m}}\left(R_{\mathrm{s}}+d R_{\mathrm{FC}}+d j \omega_{0} L_{\mathrm{FCL}}\right) \boldsymbol{I}_{\mathrm{r}}^{\mathrm{ref}} / L_{\mathrm{s}}}{\left(R_{\mathrm{s}}+d R_{\mathrm{FCL}}+d \mathrm{j} \omega_{0} L_{\mathrm{FCL}}\right) / L_{\mathrm{s}}+\mathrm{j} \omega_{0}} \\
\tau=\left(R_{\mathrm{s}}+d R_{\mathrm{FCL}}\right) / L_{\mathrm{S}} \\
\boldsymbol{I}_{\mathrm{s}}=\left(\boldsymbol{\psi}_{\mathrm{s}}-L_{\mathrm{m}} \boldsymbol{I}_{\mathrm{r}}\right) / L_{\mathrm{s}}
\end{array}\right.
$$

where $\tau$ is the damping coefficient of the stator flux, $k$ is the voltage dip depth. Superscript $\infty$ denotes the steady-state value.

To illustrate dynamics of the stator flux during the LVRT, the vector diagram of the stator flux is shown in Figure 5.

During the LVRT, the stator flux transits from the initial value $\psi_{\mathrm{s}}^{\text {ini }}$ to the post-fault steady-state value, $\psi_{\mathrm{s}}^{\infty}$.The dynamic stator flux has two components: the post-fault steadystate component and the difference between $\psi_{\mathrm{s}}^{\text {ini }}$ and $\psi_{\mathrm{s}}^{\infty}$. The latter decays with the exponential damping $e^{-\tau t}$ and rotates in the complex plane in a clockwise direction at the electrical angular speed $\left(d L_{\mathrm{FCL}} / L_{\mathrm{s}}+1\right) \omega_{0}$. As time goes on, this component gradually decreases as the stator flux approaches its post-fault steady-state value.

The analysis of the LVRT transient during voltage recovery may be derived similarly. 


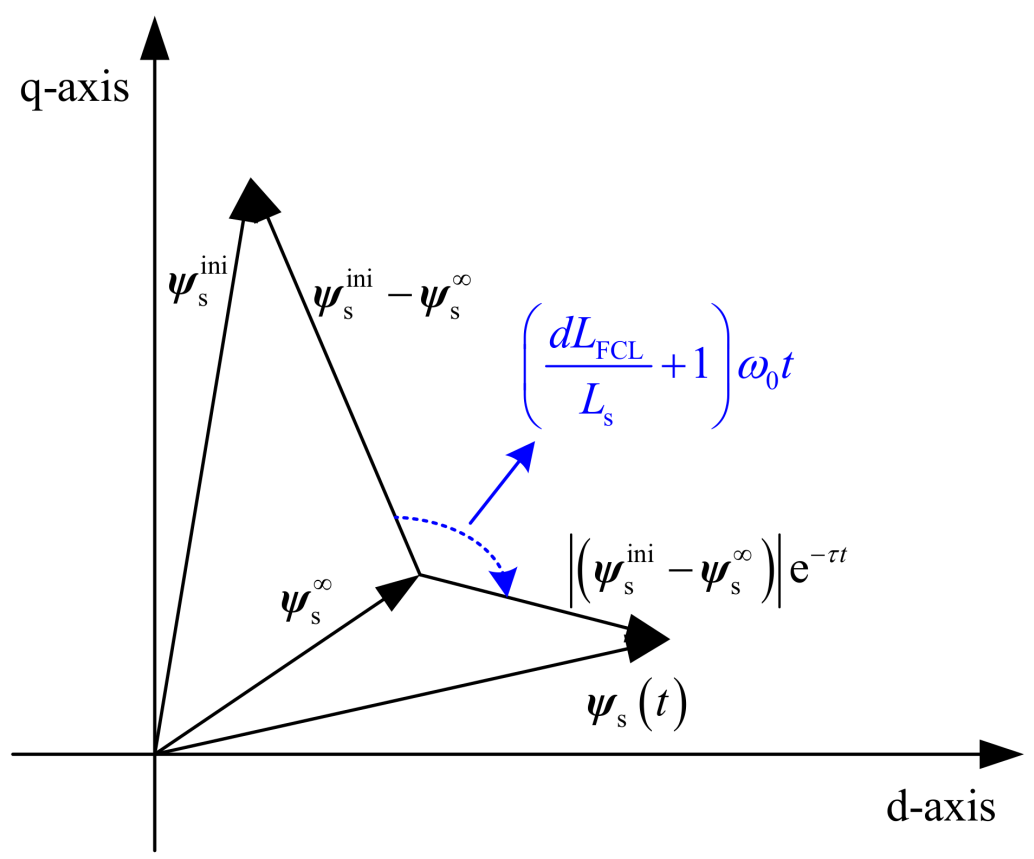

Figure 5. Vector diagram of stator flux dynamics during LVRT.

\subsection{Control of the Variable-Impedance FCL for LVRT of DFIGs}

When applying a variable-impedance FCL to the LVRT, two aspects need to be compromised in the impedance control. At the beginning period of the voltage drop, a larger impedance is preferred to reduce the oscillation of the stator current. When the current oscillation has been damped to a small aptitude, the FCL impedance needs to gradually decrease to reduce the active power consumption of the FCL. To achieve a compromise between the above two effects, the impedance of the FCL is controlled based on a weighted sum of two terms. The corresponding optimization goal is written as Equation (14), which determines the control target of the FCL impedance. For each time interval, the optimal FCL impedance is updated.

$$
\begin{aligned}
& \min W_{1} \int\left|I_{\mathrm{s}}-I_{\mathrm{s}}^{\infty}\right| \mathrm{dt}+W_{2} d R_{\mathrm{FCL}} t \\
& \text { s.t. } 0 \leq d \leq 1
\end{aligned}
$$

where $W_{1}$ and $W_{2}$ are the weight coefficients.

In Equation (14), the first term is the deviation of the stator current, which characterizes the effect of the damping to the current oscillation. The second term is the resistance of the FCL, which reflects the active power consumption. The weighted sum of the two terms works as a comprehensive criterion to control the FCL impedance. The calculation of the first term relies on the analytical calculation of the stator current, as previously derived in Equation (13). Considering that the impedance varies throughout the LVRT transient, once the optimal FCL impedance is determined for each time interval, the calculation results of the steady-state stator flux and the damping coefficient of the stator flux are updated to obtain the stator current dynamics.

As for the voltage recovery process, the impedance of the FCL is controlled in a similar way that inserts a large impedance to suppress transient oscillation yielded by the voltage rise, then gradually reduces the impedance to restore the DFIG to the pre-fault operation.

With the damping to the stator current oscillation, the second term in the optimization criterion given by Equation (14) ensures that the optimal impedance will eventually come to zero, i.e., the FCL will eventually be switched out. Thus, it is an appropriate optimization target for the control of the variable-impedance FCL. Still the weight coefficients need to be tuned to improve the LVRT performance. Setting $W_{1}$ to a high value results in slow 
switch-out of the FCL, while setting $W_{2}$ to a high value yields degraded performance in stator current oscillation suppression.

\section{Numerical Analysis}

A case study was conducted to analyze effect on the LVRT of the variable-impedance FCL. A test system with a DFIG, as shown in Figure 1, was adopted for the numerical analysis. Related parameters of the test system are listed in Table 1 [32]. Parameters of the $C_{p}$ function are given by [33].

Table 1. Parameters of the DFIG-based test system.

\begin{tabular}{ccc}
\hline Symbols & Parameters & Value/Unit \\
\hline$P_{\mathrm{N}}$ & Rated power & $1.5 \mathrm{MW}$ \\
$V_{\mathrm{N}}$ & Rated voltage & $690 \mathrm{~V}$ \\
$R_{\mathrm{S}}$ & Stator resistance & $0.00706 \mathrm{p} . \mathrm{u}$. \\
$L_{\mathrm{S}}$ & Stator inductance & $3.07 \mathrm{p} . \mathrm{u}$. \\
$R_{\mathrm{r}}$ & Rotor resistance & $0.005 \mathrm{p} . \mathrm{u}$. \\
$L_{\mathrm{r}}$ & Rotor inductance & $3.056 \mathrm{p} . \mathrm{u}$. \\
$L_{\mathrm{m}}$ & Mutual inductance & $2.9 \mathrm{p} . \mathrm{u}$. \\
$R_{\mathrm{GSC}}$ & Filter resistance of grid-side converter & $0.02 \mathrm{p} . \mathrm{u}$. \\
$L_{\mathrm{GSC}}$ & Filter inductance of grid-side converter & $0.1 \mathrm{p} . \mathrm{u}$. \\
$k_{\mathrm{p}}$ & Proportional gain of PI control & 1 \\
$k_{\mathrm{i}}$ & Integral gain of PI control & 0.1 \\
$\rho$ & Air density & $1.225 \mathrm{~kg} / \mathrm{m}^{3}$ \\
$R$ & Radius of wind turbine & $32.13 \mathrm{~m}$ \\
\hline
\end{tabular}

The introduced LVRT scenario is as follows: the stator voltage drops to from 1 p.u. to 0.2 p.u. at $t=0.1 \mathrm{~s}$ and lasts for $0.625 \mathrm{~s}$ (the LVRT requirement of the Chinese grid code) [34]. At $\mathrm{t}=0.725 \mathrm{~s}$, the stator voltage recovers to 1 p.u.

\subsection{Verification of LVRT Analysis}

In this section, the accuracy of the analysis of the LVRT transient is validated. Under normal operation, the rotor current reference is $0.4891-\mathrm{j} 0.3239$ p.u. During the LVRT, the rotor current reference is set to $1.05-\mathrm{j} 0.3 \mathrm{p}$.u. The resistance and reactance of the FCL are set to 0.1 p.u. and 0.15 p.u., respectively. As for the rotor current and stator current, the calculation results obtained from the analytical model are compared with the time-domain simulation results, as shown in Figures 6 and 7.

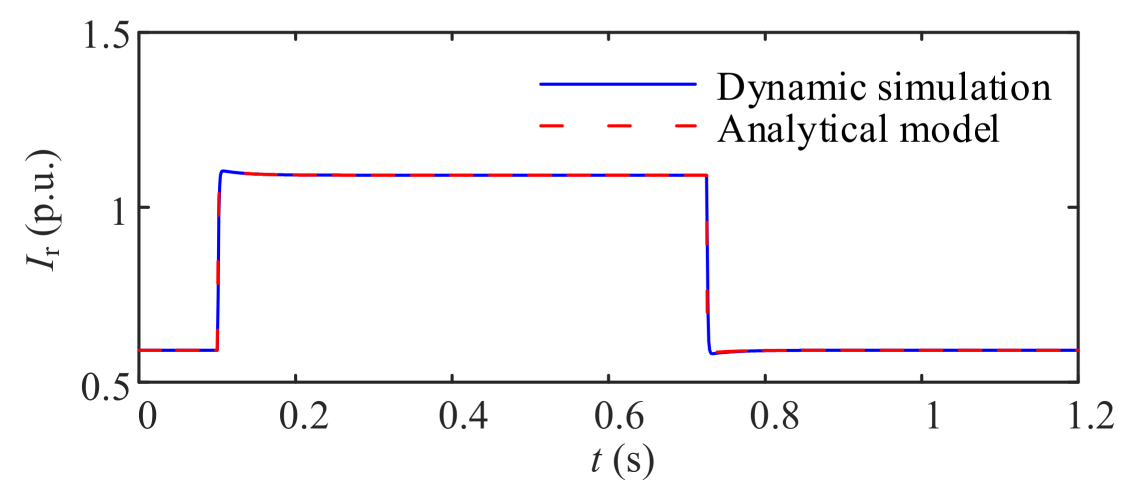

Figure 6. Comparison between analytical calculation and simulation results of rotor current. 


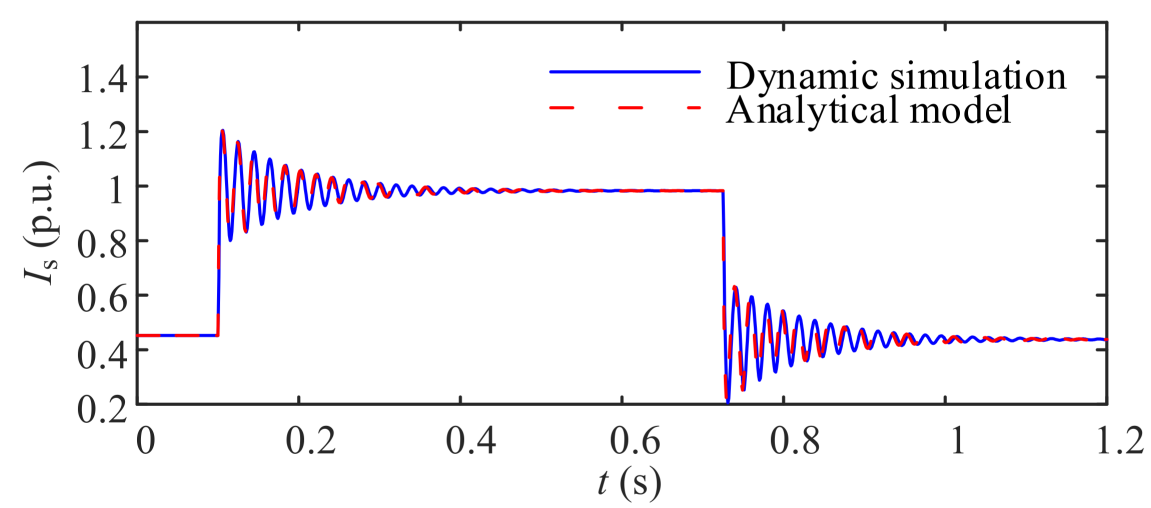

Figure 7. Comparison between analytical calculation and simulation results of stator current.

The analytical calculation and simulation results were obtained based on the same modelling of the DFIG. The simulation results were directly obtained by solving the differential-algebra equation set of the DFIG model using the numerical algorithm. Simulations are easily carried out, but they are incapable of providing direct quantification of the studied parameters (rotor and stator current in this case) and require great computational effort. The analytical calculation derives the expression of the studied parameter based on the same system model. Thus, the analytical calculations are capable of obtaining the same results as the simulations do.

As seen from the above figures, the analytical calculation results are consistent with the dynamic simulation results, which verifies the accuracy of the analytical LVRT analysis. It can also be seen that the rotor current quickly reaches the reference value, which verifies the assumption adopted to solve the stator current.

As seen in Figure 6, the rotor current increases during the transient, which results from the change in the rotor current reference. During the LVRT of the DFIG, the rotor current reference is adjusted to $1.05-\mathrm{j} 0.3 \mathrm{p}$.u. from its pre-fault value, $0.4891-\mathrm{j} 0.3239 \mathrm{p} . \mathrm{u}$. The increase in the direct axis rotor current reference (from 0.4891 to 1.05) leads to the increase in the rotor current. The direct axis rotor current is related to the active power control of the DFIG, and it is increased to enhance the active power output capability, which helps to support the frequency stability of the wind power system during the LVRT.

Based on the analytical expression of the stator current (Equation (13)), the properties of the transient stator current oscillation shown in Figure 7 were analyzed. The decay of the stator current oscillation is related to the time constant, i.e., $\left(R_{\mathrm{S}}+d R_{\mathrm{FCL}}\right) / L_{\mathrm{S}}$, while the period of the stator current oscillation is obtained based on the electrical angular speed, i.e., $\left(d L_{\mathrm{FCL}} / L_{\mathrm{S}}+1\right) \omega_{0}$.

\subsection{Comparison between LVRT Effects with Variable- and Fixed-Impedance FCL}

In this section, the LVRT effects of the variable- and fixed-impedance FCL are compared to show the improvement brought by the variable impedance. The impedance of the FCL is adjusted to strike a balance between the damping of the current oscillation and the active power consumption of the FCL. The maximum resistance and reactance of the FCL are set to 0.5 p.u. and 0.75 p.u., respectively. The resistance of the FCL, based on the optimization target (Equation (14)), is shown in Figure 8. The reactance of the FCL is in proportion to the resistance, thus has a similar profile. It is not given here to avoid redundancy.

From the above figure, it can be seen that the resistance of the FCL is set to a high value to suppress the transient oscillation of the stator current, and then it gradually decreases to reduce the consumption of the stator active power. A similar switch-out process of the FCL with its impedance gradually approaching zero is observed at the voltage recovery stage.

The LVRT effect of the variable-impedance FCL is compared to those with the fixedimpedance FCLs. Three impedance values, $0+$ j0 p.u. (i.e., No FCL), $0.2+$ j0.3 p.u., and $0.4+$ j0.6 p.u., are set in the fixed-impedance FCL group. The comparison of the stator 
current, stator voltage, rotor voltage, active power output of the stator, and the active power consumption of the FCL are shown in Figures 9-13, respectively.

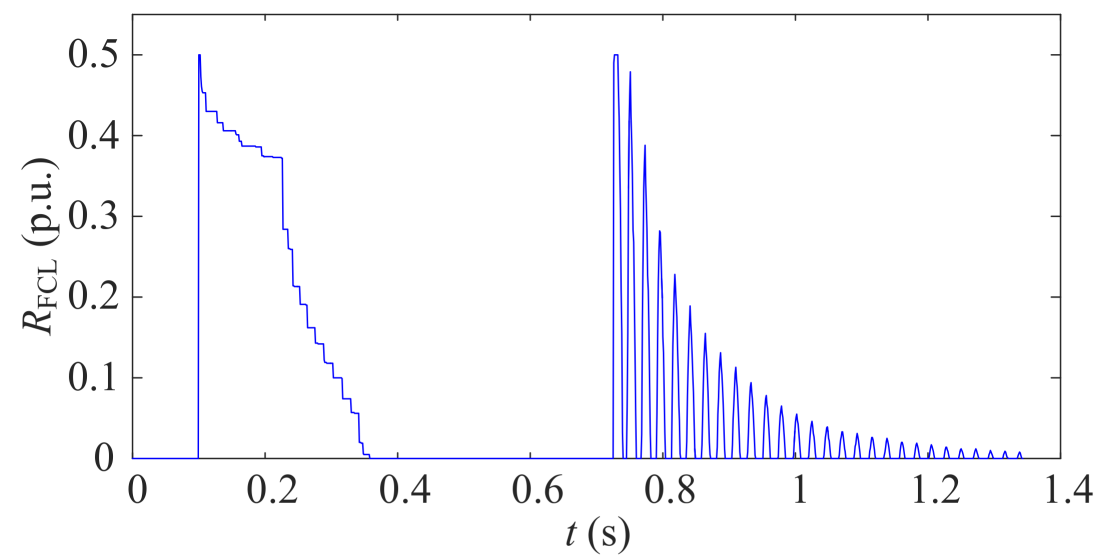

Figure 8. Control to variable-impedance FCL during LVRT.

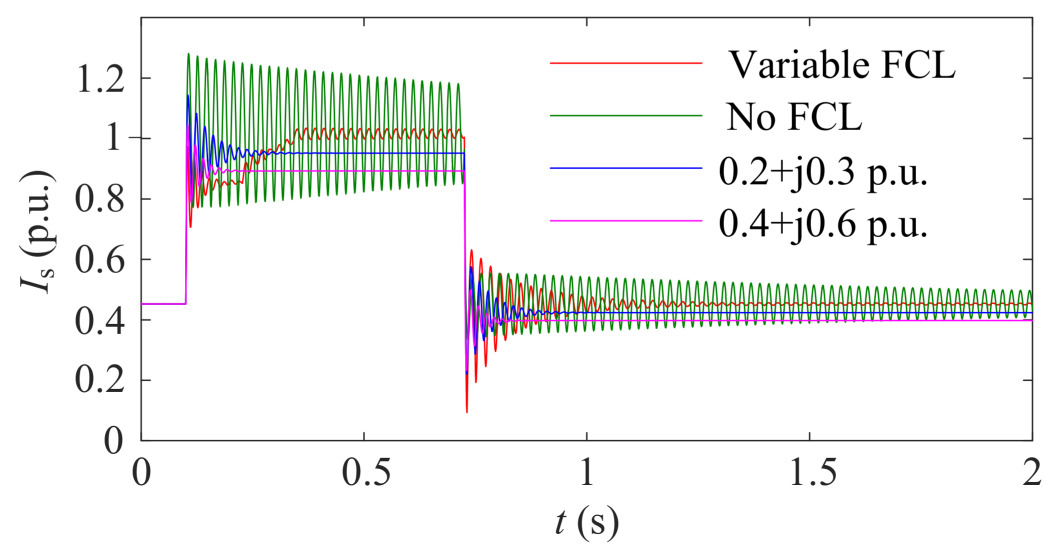

Figure 9. Comparison of stator current between variable- and fixed-impedance FCLs.

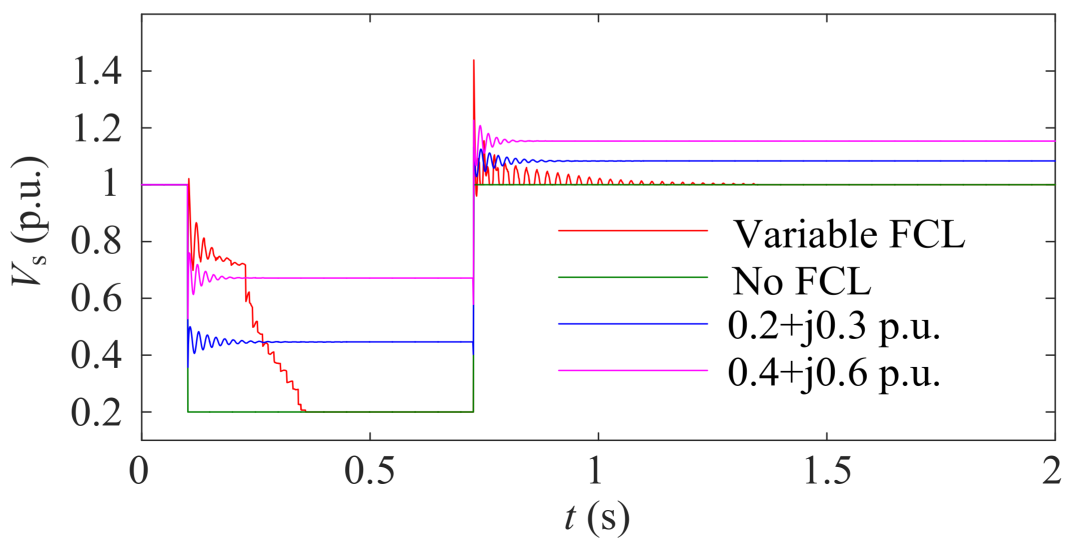

Figure 10. Comparison of stator voltage between variable- and fixed-impedance FCLs. 


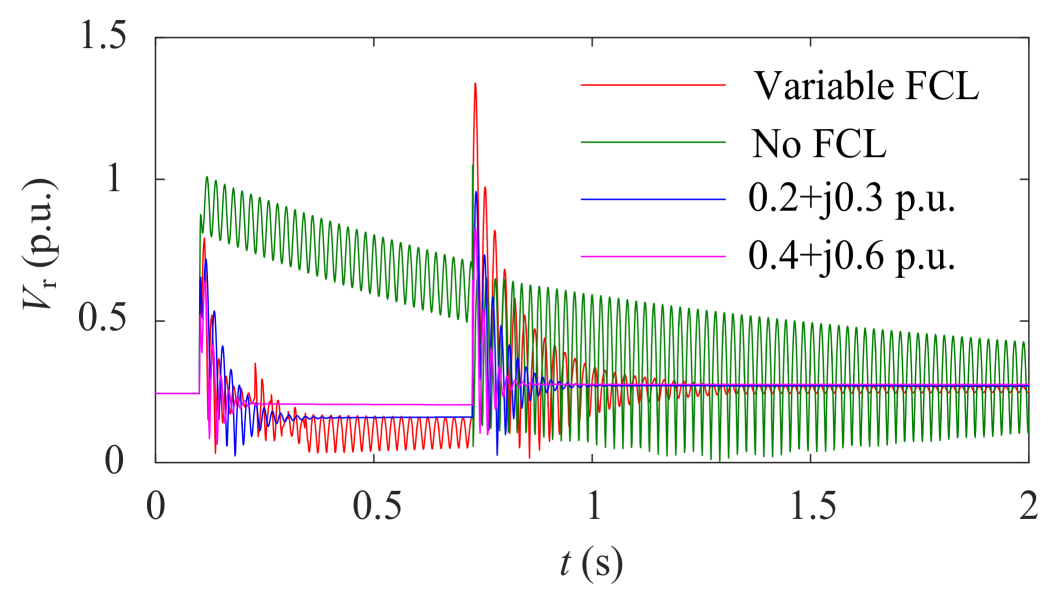

Figure 11. Comparison of rotor voltage between variable- and fixed-impedance FCLs.

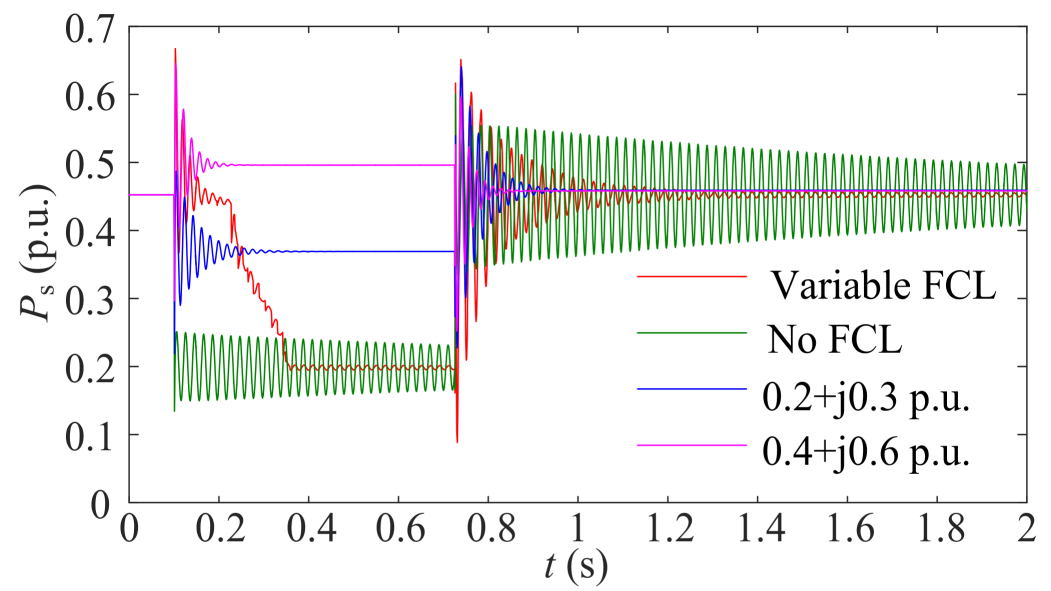

Figure 12. Comparison of stator active power between variable- and fixed-impedance FCLs.

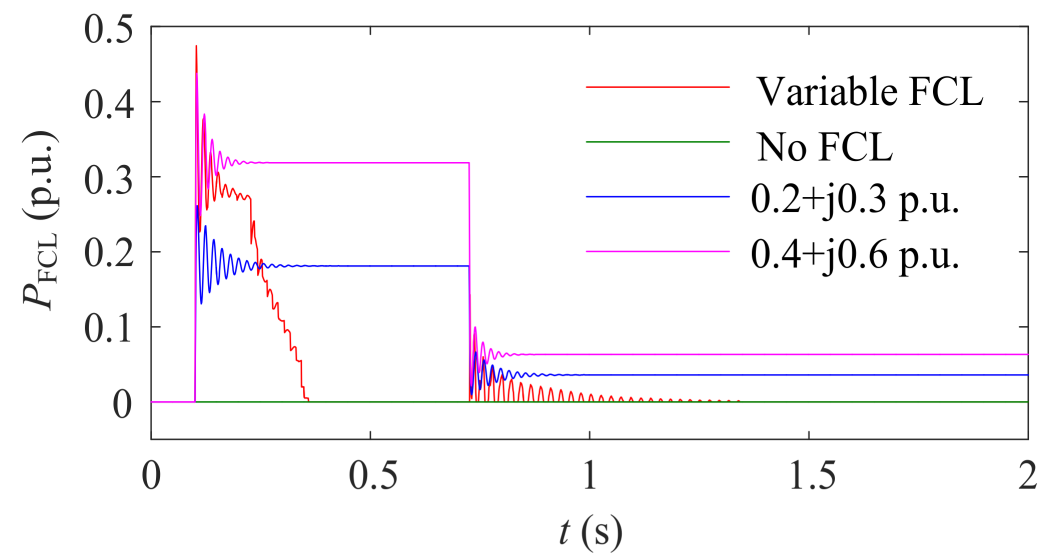

Figure 13. Comparison of active power consumption of variable- and fixed-impedance FCLs.

As seen from Figures 9 and 11, with the higher impedance of the FCL, the current oscillation is suppressed and damped at a faster rate. Considering that the change rate of the stator flux is introduced to the RSC control as the feed-forward compensation term, the rotor voltage rise is also suppressed with the higher impedance of the FCL. These are the advantages of adopting an FCL with high impedance to assist the LVRT.

In the meantime, the high impedance FCL reduces the active power output capability of the DFIG during the LVRT. As for the simulation scenario adopted in this section, the rotor current references are set to the same values, which means that the same active power 
output of the DFIG is delivered to the integrated grid. As seen from Figures 12 and 13, apparently the active power of the stator is increased with the high impedance FCL to support the stator voltage (seen in Figure 10). However, the increased stator active power does not contribute to the active power output delivered to the integrated grid but dissipates in the FCL. As shown in Figure 12, with the fixed impedance $0.4+j 0.6$ p.u., the active power of the stator already exceeds its pre-fault value. In this case, if the active current reference is further increased to provide more active power for the grid frequency support, the stator active power will rise to a higher value with the high impedance FCL, leading to serious deacceleration of the DFIG.

With control of the variable-impedance FCL, the advantages of the high impedance FCL scheme and the no FCL scheme are retained while their disadvantages are avoided. With the adjustable impedance value ranging from $0+j 0$ to $0.5+0.75 \mathrm{p} . \mathrm{u}$., the large impedance is applied at the early stage of the LVRT to effectively constrain the stator current oscillation. Then the impedance is gradually reduced to switch out the FCL. Its active power consumption is reduced while the stator current oscillation is still constrained to a low amplitude.

As for the above simulations of the fixed-impedance FCLs, the transient process of their switch-out are not considered, which is another important aspect to consider for the operation of the FCL, as they eventually need to be switched out to let the DFIG return to its pre-fault condition during the voltage recovery. In Figure 10, the fixed-impedance FCL stays switched in during the whole LVRT process. Thus, during the voltage recovery stage (after $0.725 \mathrm{~s}$ ), the grid voltage recovers to the reference while the generator terminal voltage (stator voltage) is further boosted due to the switched-in FCL, i.e., the stator voltage rises to a value higher than the pre-fault reference. This is likely to cause violations of the security constraint of the stator voltage. Thus, the fixed-impedance FCL needs to be switched out during the voltage recovery stage.

As for the voltage dip ride-through process, the fixed-impedance FCL needs to be switched out to restore the DFIG to normal operation condition, i.e., the stator voltage is restored to the pre-fault reference. Additionally, switching the FCL out early helps to avoid the impact of accumulated heat on the security properties of the FCL. The smooth switch-out is another advantage of the control to the variable-impedance FCL. With the switch-out process of the FCL considered, the LVRT effects are further compared, as shown in Figures 14-16. The fixed-impedance FCLs are switched in at $t=0.1 \mathrm{~s}$ and $t=0.725 \mathrm{~s}$ to deal with the voltage dip and recovery. They stay switched in for $0.1 \mathrm{~s}$, then they are switched out.

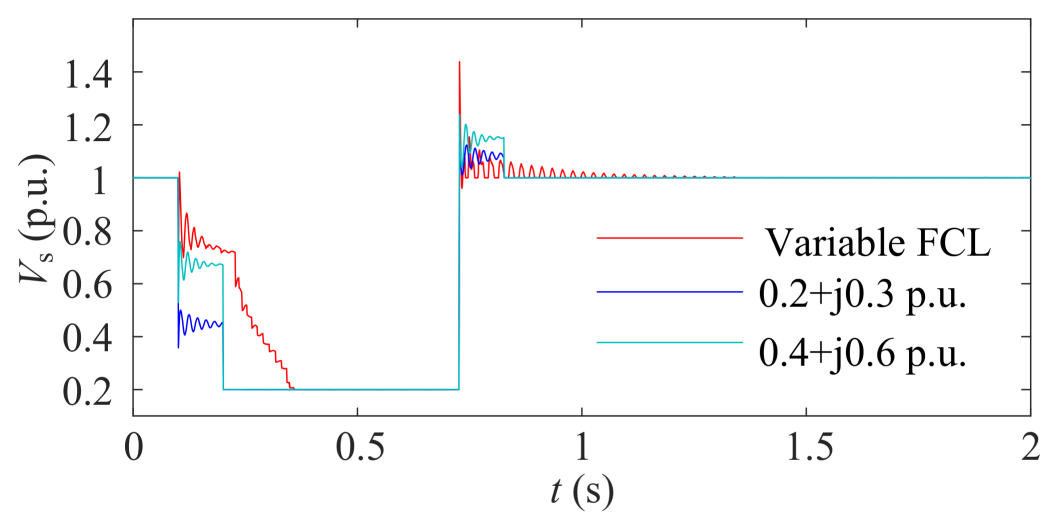

Figure 14. Stator voltage considering switch-out of variable- and fixed-impedance FCLs. 


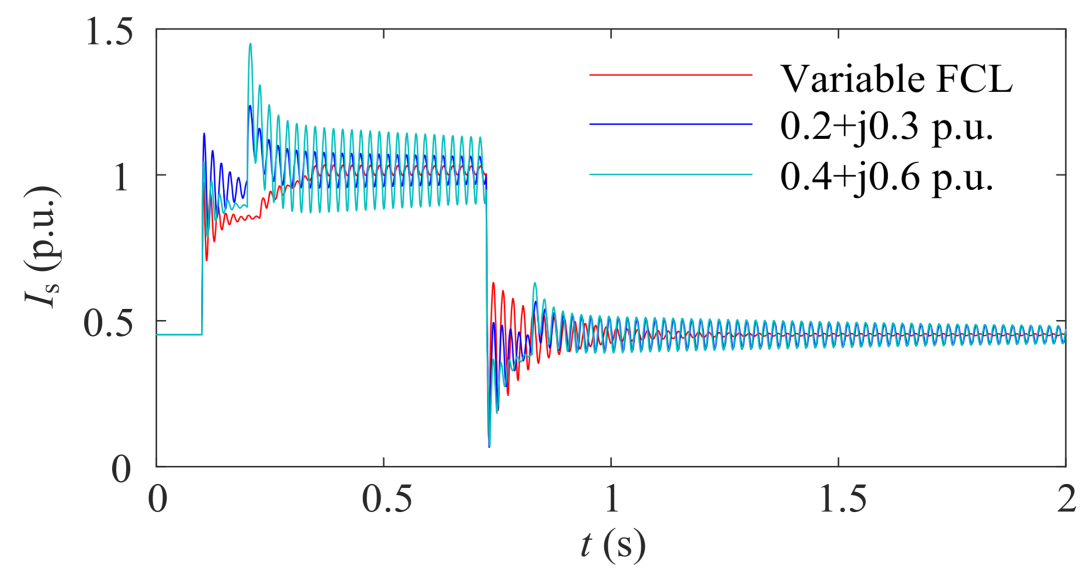

Figure 15. Stator current considering switch-out of variable- and fixed-impedance FCLs.

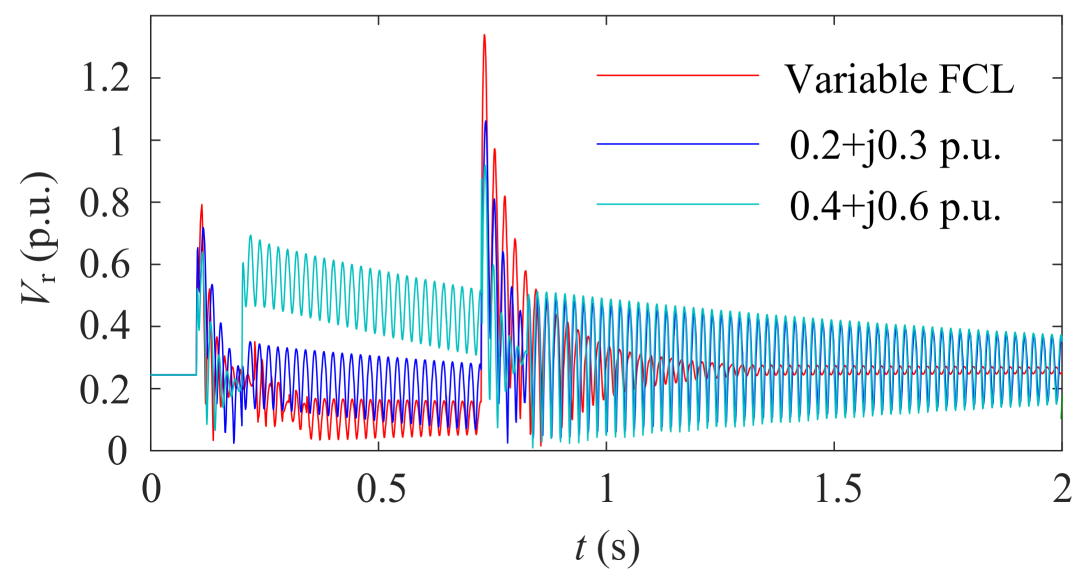

Figure 16. Rotor voltage considering switch-out of variable- and fixed-impedance FCLs.

As can be seen from the above figures, for both the voltage dip and voltage recovery processes, abrupt changes in the stator voltage occur immediately following the direct switch-out of the fixed-impedance FCL. Once again, oscillations of the stator current are the result, especially with the large impedance. For example, with a fixed-impedance of $0.4+$ j0.6 p.u., the switch-out of the FCL yields severe voltage dips, leading to high amplitude stator current oscillation. The rotor voltage is increased to compensate for the stator flux oscillation. In contrast, with control of the variable-impedance FCL, its impedance is gradually decreased to switch out the FCL. The amplitude of the stator current oscillation is low during the voltage dip ride-through, which also helps to quickly restore the DFIG to its pre-fault working condition at the voltage recovery stage.

\subsection{Analysis of the Impact of Weight Coefficient Settings}

Control of the variable-impedance FCL is affected by the settings of the weight coefficients. With the weight coefficient $W_{1}$ set to 1 , the LVRT effects of different values of the weight coefficient, $W_{2}$, are compared in Figures 17-19.

As can be seen from the above figures, control of the variable-impedance FCL may be alternated by adjusting the weight coefficients in the optimization target. With a larger value of $W_{2}$, the control of the variable-impedance FCL puts more emphasis on reducing the active power consumption of the $\mathrm{FCL}$, in which case the impedance value is decreased at a faster rate (seen from Figure 17) to reduce the consumed active power (seen from Figure 19). This is realized at the cost of reduced damping of the stator current oscillation (seen from Figure 18). The flexibility of the control over the variable-impedance FCL lies in adjusting the weight coefficients, whereby the FCL may be controlled to deal with intense 
oscillations yielded by severe voltage dips (increasing $W_{1}$ ) or to quickly switch out without consuming large amounts of active power (increasing $W_{2}$ ).

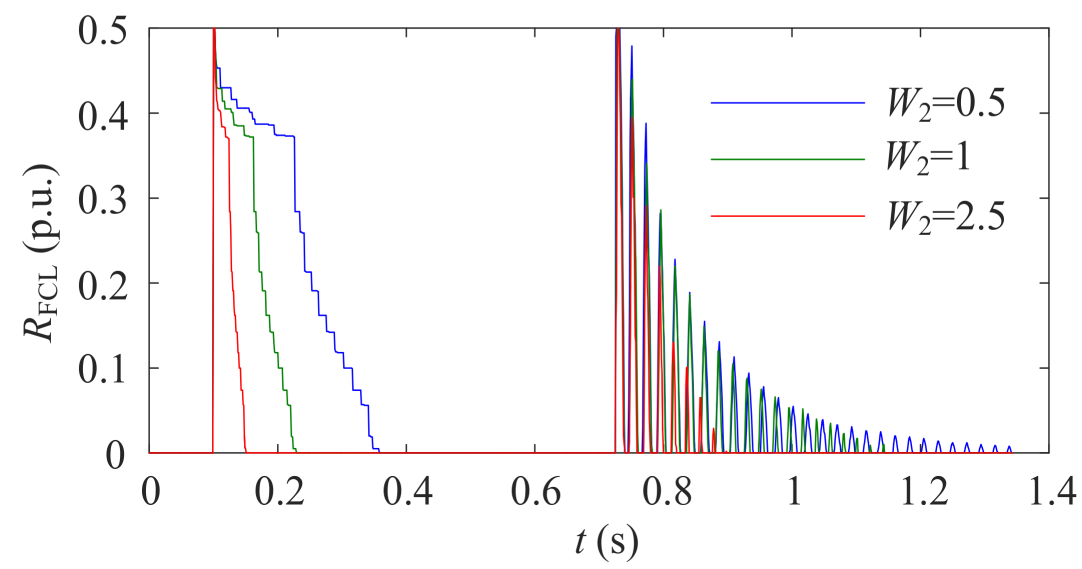

Figure 17. Resistance of the variable-impedance FCL with different weight coefficients.

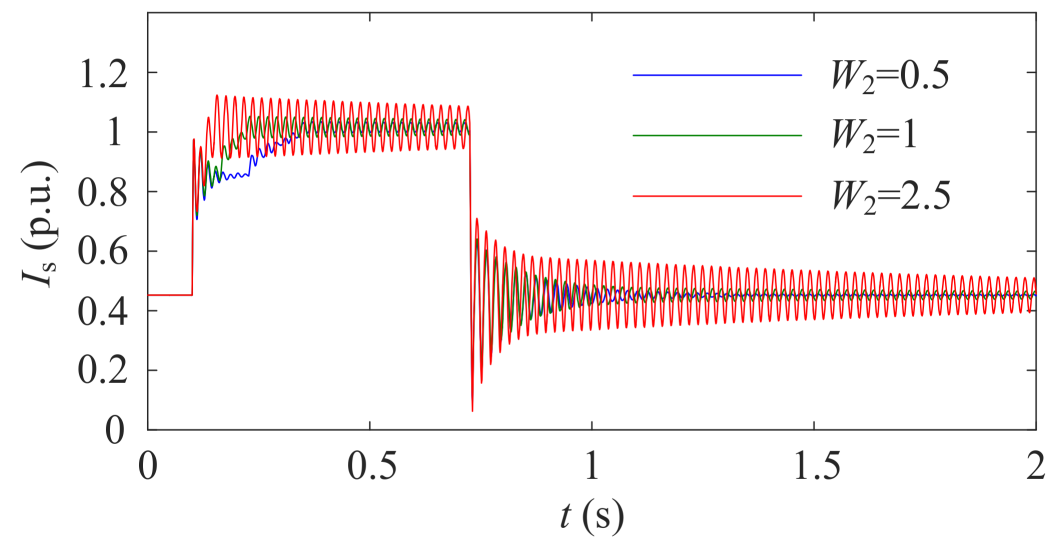

Figure 18. Stator current with control of the variable-impedance FCL adopting different weight coefficients.

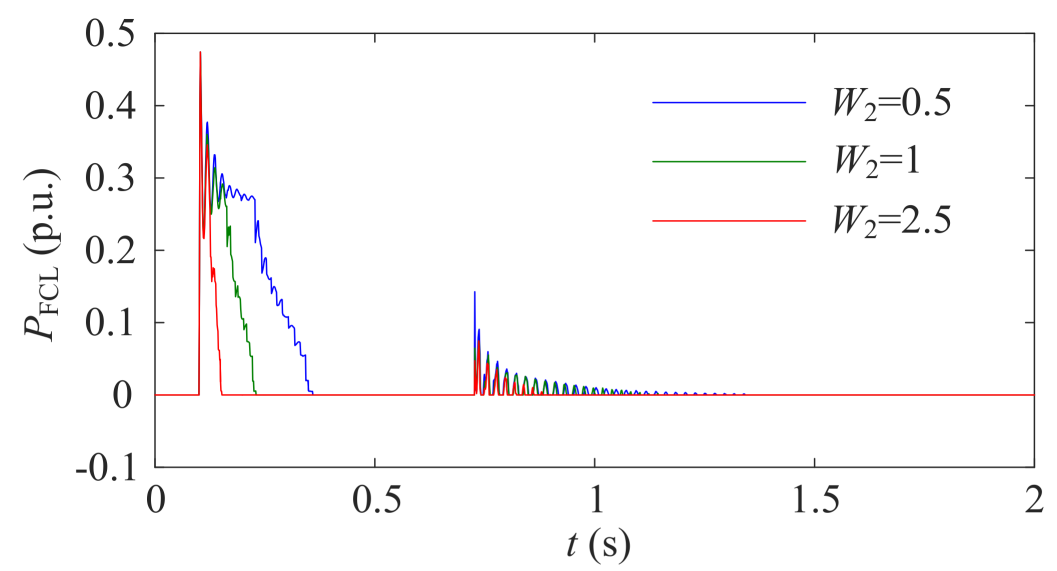

Figure 19. Active power consumption of the FCL with control of the variable-impedance FCL adopting different weight coefficients.

\subsection{Adaptivity to Different Levels of Voltage Dips}

Compared with the fixed-impedance FCL, another advantage of the variable-impedance FCL is that its impedance may be flexibly adjusted to adapt to different levels of voltage dips. In this section, a different LVRT scenario is introduced with the voltage dropping to 
0.6 p.u. The impedance of the fixed-impedance FCL is set to $0.5+j 0.75$ p.u., which equals the maximum impedance value of the variable-impedance FCL. The LVRT effects with fixed- and variable-impedance FCLs, as well as the no FCL condition are compared in Figures 20 and 21.

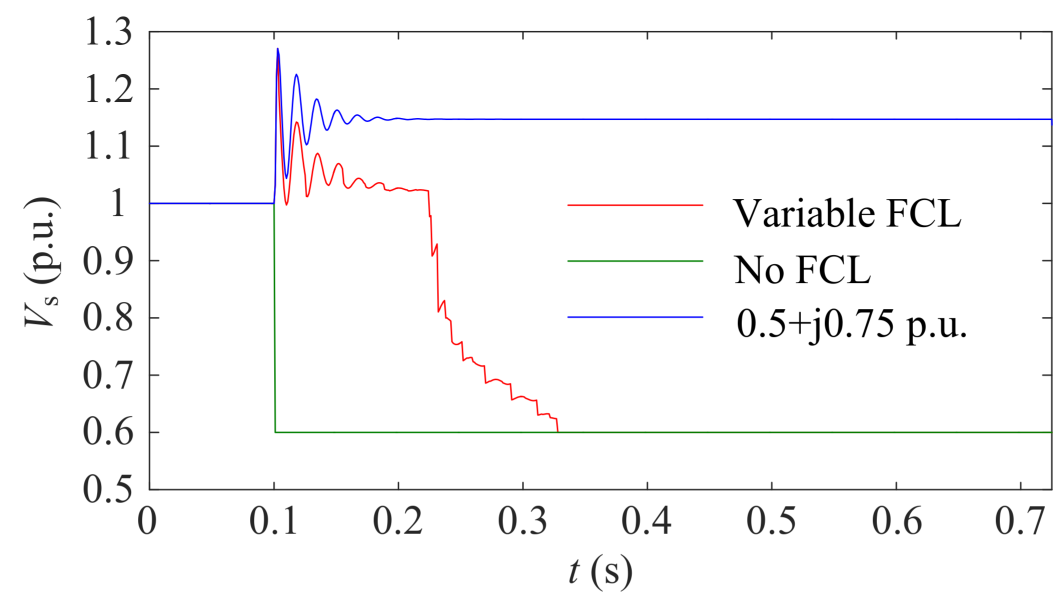

Figure 20. Stator voltage with different control schemes of the FCL under minor voltage dip.

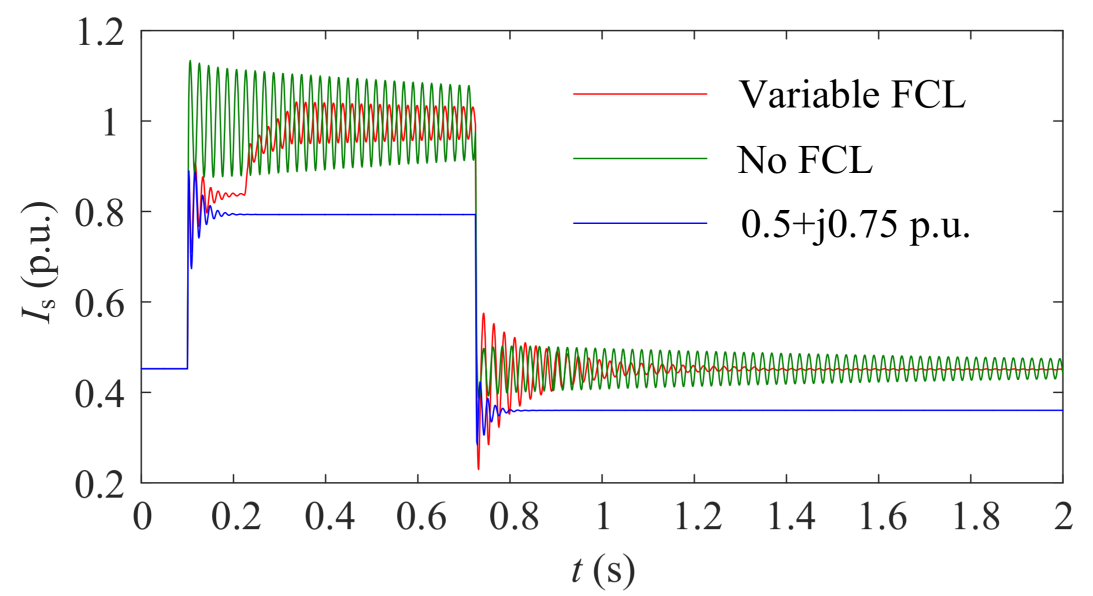

Figure 21. Stator current with different control schemes of the FCL under minor voltage dip.

As can be seen from Figure 20, when a minor voltage dip occurs, the switch-in of large impedance FCL (0.5 + j0.75 p.u.) yields a high stator voltage that exceeds its nominal value. When the stator voltage constraint is considered, the fixed-impedance FCL may not be allowed to switch in, which will result in the undamped stator current oscillation as shown by the simulation result of the no FCL scenario in Figure 21. With the variableimpedance used to assist the LVRT, the high impedance is only applied at the early stage of the LVRT to suppress the inrush fault current. The stator overvoltage is relieved by gradually reducing the impedance value. Still, during this process, the oscillation of the stator current is constrained to comparatively small amplitudes (seen from Figure 21). More security constraints like the stator voltage constraint may be added as constraints to control the impedance of the FCL for the improved LVRT performance.

\subsection{Verification of Improvement to the Control Strategy for Variable-Impedance the FCL}

In this section, the effects of the control strategies for the variable-impedance FCL are compared to show improvements due to the proposed control scheme. With the same LVRT scenario applied in Section 4.2, the impedance of the FCL is controlled by the ramp function as well as the proposed control scheme. With the ramp function, the impedance of the FCL is controlled with different slope coefficients. The resistance of the FCL with the ramp function control is illustrated in Figure 22. 


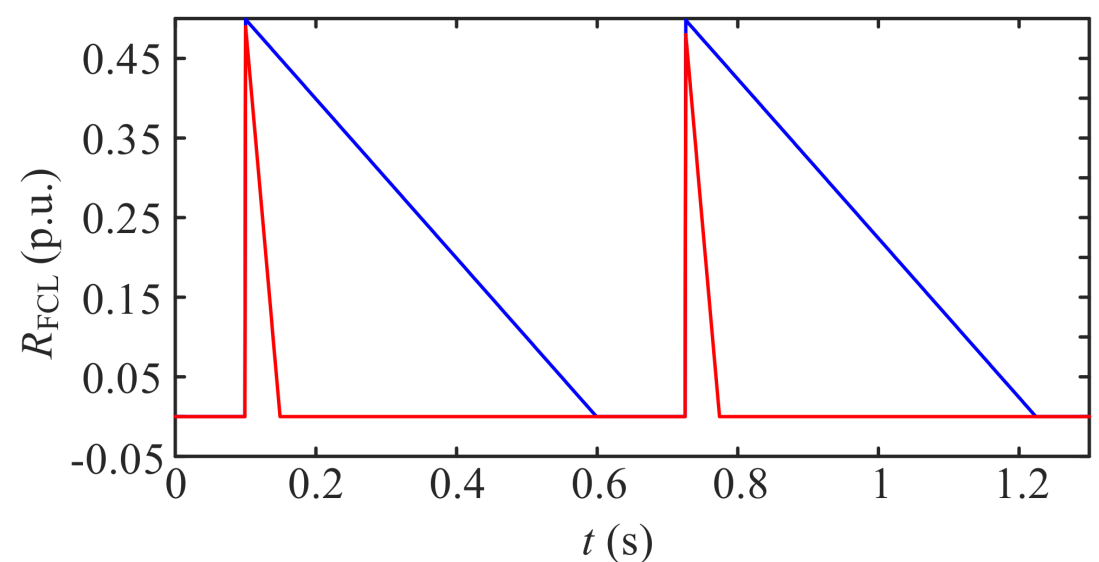

\section{Ramp function with small slope coefficient Ramp function with large slope coefficient}

Figure 22. Control of the variable-impedance FCL based on the ramp function.

As shown in Figure 22, the impedance of the FCL is controlled by ramp functions with large and small slope coefficients. In the case of the large slope coefficient, the impedance of the FCL is decreased at a faster rate, i.e., the FCL is more quickly switched out after its switch-in to deal with abrupt stator voltage changes.

With different control strategies for the variable-impedance FCL, the stator current, stator voltage, and active power consumption of the FCL are compared in Figures 23-25, respectively.
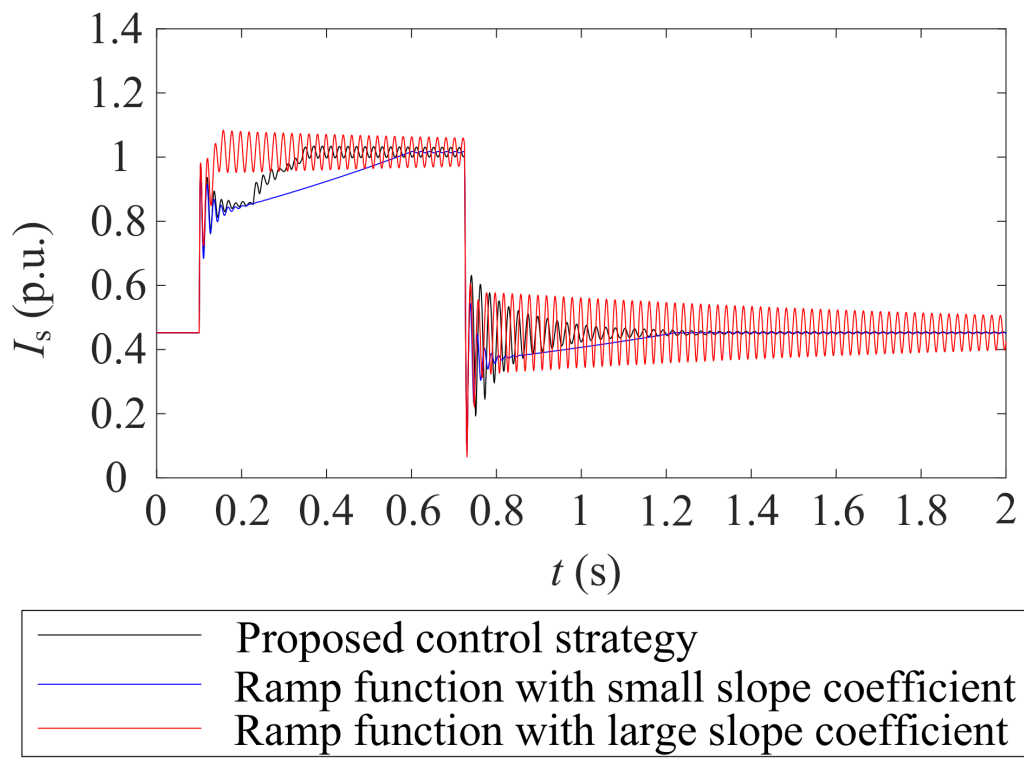

Figure 23. Stator current with different control strategies of variable-impedance FCL. 

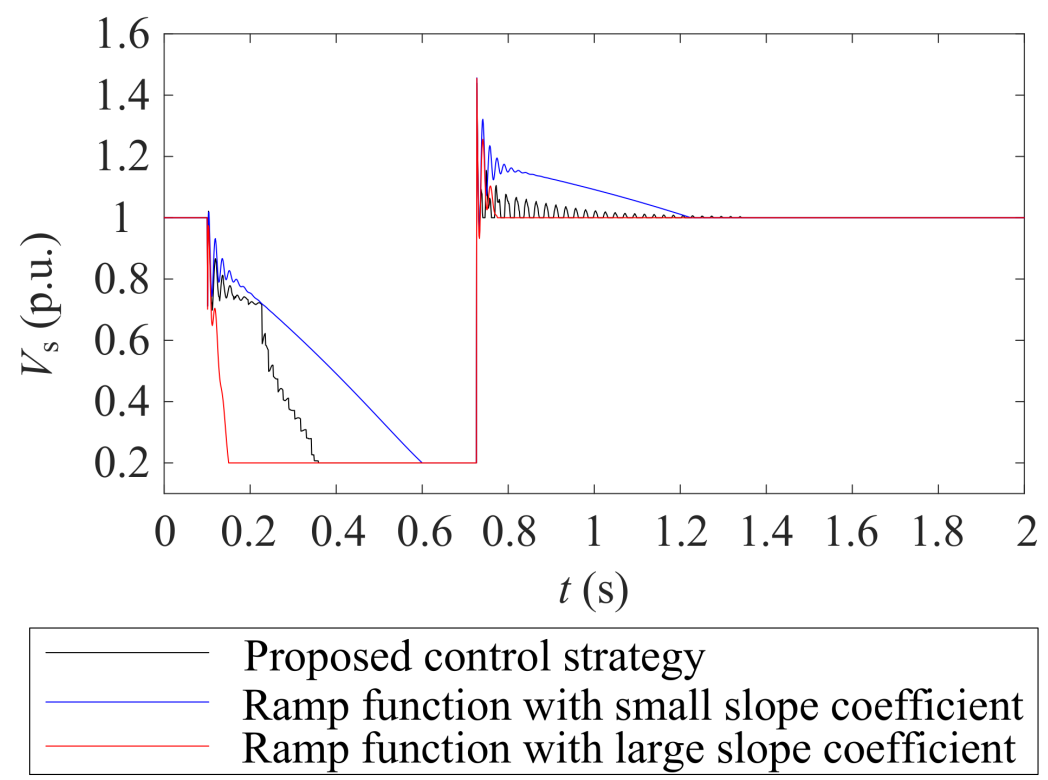

Figure 24. Stator voltage with different control strategies of variable-impedance FCL.

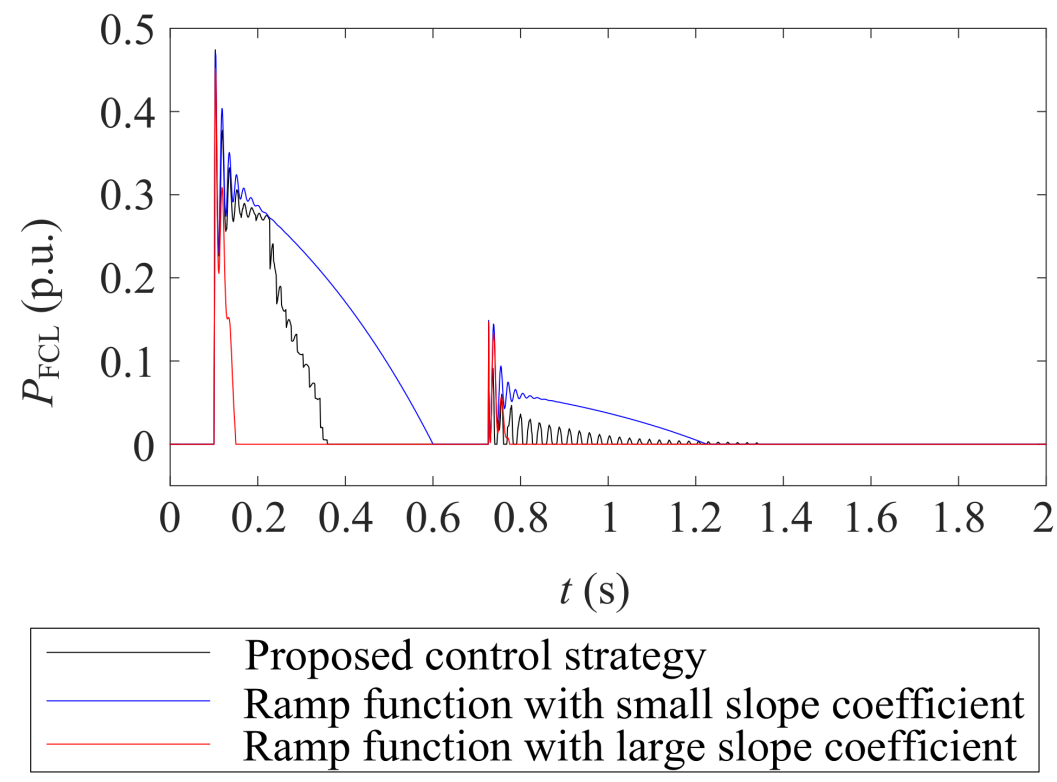

Figure 25. Active power consumption of FCL with different control strategies of variableimpedance FCL.

From the above comparison results it can be seen that the effect of the variableimpedance FCL controlled by the ramp function to assist the LVRT is affected by the slope coefficient. With a large slope coefficient, the impedance of the FCL is quickly reduced, thus it fails to provide sufficient damping to the stator current oscillation (seen from Figure 23). With a small slope coefficient, the impedance of the FCL remains effective longer, which not only yields a long period of stator overvoltage (seen from Figure 24), but also consumes large amount of active power during the LVRT (seen from Figure 25). With the proposed strategy, the need for effective damping of current oscillation and timely switch-out of the FCL are compromised, thus the proposed control strategy achieves improved overall LVRT performance in comparison with the ramp function control. 


\section{Conclusions}

In this paper, a novel control methodology for variable-impedance FCLs to assist the LVRT of DFIGs was proposed. First, the RSC control of the DFIG was coordinated with the FCL implemented on the stator side. Then the analysis of the LVRT transient of the DFIG was carried out to quantify the LVRT effects with the different impedances of the FCL. During the LVRT process, including the voltage dip and the voltage recovery stages, the impedance of the FCL is controlled based on optimization to a comprehensive index considering both the ability to suppress the stator current oscillation and the active power consumption of the FCL. Based on the numerical analysis results, the following conclusions were drawn:

(i) The LVRT analysis of the DFIG shows satisfactory accuracy compared with timedomain simulation results.

(ii) With the proposed control scheme of the variable-impedance FCL, its impedance is gradually decreased to ensure timely switch-out of the FCL while constraining the stator current oscillation. The control scheme works like a soft switch for inserted FCL impedance, which helps to improve the LVRT performance compared with fixed-impedance FCLs as well as variable-impedance FCLs with the comparatively simple control (e.g., the ramp function control).

(iii) The control scheme of the variable-impedance FCL provides flexibility in control, e.g., the control target may be flexibly adjusted by changing the weight coefficients of the optimization index. Moreover, new optimization targets (e.g., reactive current injection capability) and constraints (e.g., stator voltage constraint) may be added as extensions to the existing scheme to realize the desired LVRT performance through control of the variable-impedance FCL.

Author Contributions: Conceptualization, J.H. and S.S.; methodology, J.H.; software, J.H.; validation, S.S. and L.Z.; formal analysis, J.H.; investigation, L.Z.; resources, X.X.; data curation, J.H.; writingoriginal draft preparation, J.H.; writing—-review and editing, J.H.; visualization, T.S.; supervision, T.S.; project administration, L.Z.; funding acquisition, S.S. and L.Z. All authors have read and agreed to the published version of the manuscript.

Funding: This research was funded by the Natural Science Foundation of Jiangsu Province, grant number BK20200969, Key Laboratory of Control of Power Transmission and Conversion (SJTU), Ministry of Education, grant number 2021AC03, and Nantong Science and Technology Plan Project, grant number JC2021107 and JC2021105.

Conflicts of Interest: The authors declare no conflict of interest.

\section{References}

1. Tian, P.; Hao, Z.; Li, Z. Doubly-Fed Induction Generator Coordination Control Strategy Compatible with Feeder Automation. Electronics 2020, 9, 18. [CrossRef]

2. Mohammadi, J.; Vaez-Zadeh, S.; Afsharnia, S.; Daryabeigi, E. A Combined Vector and Direct Power Control for DFIG-Based Wind Turbines. IEEE Trans. Sustain. Energy 2014, 5, 767-775. [CrossRef]

3. Mossa, M.A.; Echeikh, H.; Diab, A.A.Z.; Quynh, N.V. Effective Direct Power Control for a Sensor-Less Doubly Fed Induction Generator with a Losses Minimization Criterion. Electronics 2020, 9, 1269. [CrossRef]

4. Sang, S.; Gao, N.; Cai, X.; Li, R. A Novel Power-Voltage Control Strategy for the Grid-Tied Inverter to Raise the Rated Power Injection Level in a Weak Grid. IEEE J. Emerg. Sel. Top. Power Electron. 2018, 6, 219-232. [CrossRef]

5. Rahman, S.; Khan, I.; Alkhammash, H.I.; Nadeem, M.F. A Comparison Review on Transmission Mode for Onshore Integration of Offshore Wind Farms: HVDC or HVAC. Electronics 2021, 10, 1489. [CrossRef]

6. Liu, R.; Yao, J.; Wang, X.; Sun, P.; Pei, J.; Hu, J. Dynamic Stability Analysis and Improved LVRT Schemes of DFIG-Based Wind Turbines during a Symmetrical Fault in a Weak Grid. IEEE Trans. Power Electron. 2020, 35, 303-318. [CrossRef]

7. Kaloi, G.S.; Baloch, M.H.; Kumar, M.; Soomro, D.M.; Chauhdary, S.T.; Memon, A.A.; Ishak, D. An LVRT Scheme for Grid Connected DFIG Based WECS Using State Feedback Linearization Control Technique. Electronics 2019, 8, 777. [CrossRef]

8. Tohidi, S.; Behnam, M. A Comprehensive Review of Low Voltage Ride through of Doubly Fed Induction Wind Generators. Renew. Sustain. Energy Rev. 2016, 57, 412-419. [CrossRef]

9. Gao, W.; Wang, G.; Ning, J. Development of Low Voltage Ride-Through Control Strategy for Wind Power Generation Using Real Time Digital Simulator. In Proceedings of the 2009 IEEE/PES Power Systems Conference and Exposition, Seattle, WA, USA, 15-17 March 2009. [CrossRef] 
10. Hu, J.; He, Y. Dynamic Modelling and Robust Current Control of Wind-Turbine Driven DFIG during External AC Voltage Dip. J. Zhejiang Univ.-Sci. A 2006, 7, 1757-1764. [CrossRef]

11. Liang, J.; Qiao, W.; Harley, R.G. Feed-Forward Transient Current Control for Low-Voltage Ride-Through Enhancement of DFIG Wind Turbines. IEEE Trans. Energy Convers. 2010, 25, 836-843. [CrossRef]

12. Vidal, J.; Abad, G.; Arza, J.; Aurtenechea, S. Single-Phase DC Crowbar Topologies for Low Voltage Ride Through Fulfillment of High-Power Doubly Fed Induction Generator-Based Wind Turbines. IEEE Trans. Energy Convers. 2013, 28, 768-781. [CrossRef]

13. Pannell, G.; Atkinson, D.J.; Zahawi, B. Minimum-Threshold Crowbar for a Fault-Ride-Through Grid-Code-Compliant DFIG Wind Turbine. IEEE Trans. Energy Convers. 2010, 25, 750-759. [CrossRef]

14. Islam, M.M.; Muttaqi, K.M.; Sutanto, D. A Novel Saturated Amorphous Alloy Core Based Fault Current Limiter for Improving the Low Voltage Ride Through Capability of Doubly-Fed Induction Generator Based Wind Turbines. IEEE Trans. Ind. Appl. 2021, 57, 2023-2034. [CrossRef]

15. Gururaj, M.V.; Padhy, N.P. PHIL Experimentation on Fault Ride through Behavior of Doubly Fed Induction Generator-Based Wind System in the Presence of Fault Current Limiter. IEEE Trans. Ind. Appl. 2020, 56, 2988-3005. [CrossRef]

16. Wessels, C.; Gebhardt, F.; Fuchs, F.W. Fault Ride-Through of a DFIG Wind Turbine Using a Dynamic Voltage Restorer during Symmetrical and Asymmetrical Grid Faults. IEEE Trans. Power Electron. 2011, 26, 807-815. [CrossRef]

17. Ramirez, D.; Martinez, S.; Platero, C.A.; Blazquez, F.; de Castro, R.M. Low-Voltage Ride-through Capability for Wind Generators Based on Dynamic Voltage Restorers. IEEE Trans. Energy Convers. 2011, 26, 195-203. [CrossRef]

18. Montazeri, M.M.; Xu, D.; Yuwen, B. Improved Low Voltage Ride Through Capability of Wind Farm Using STATCOM. In Proceedings of the 2011 IEEE International Electric Machines \& Drives Conference, Niagara Falls, ON, Canada, 15-18 May 2011. [CrossRef]

19. Morren, J.; de Haan, S.W.H. Ridethrough of Wind Turbines with Doubly-Fed Induction Generator during a Voltage Dip. IEEE Trans. Energy Convers. 2005, 20, 435-441. [CrossRef]

20. Elshiekh, M.E.; Mansour, D.A.; Azmy, A.M. Improving Fault Ride-Through Capability of DFIG-Based Wind Turbine Using Superconducting Fault Current Limiter. IEEE Trans. Appl. Supercond. 2013, 23, 5601204. [CrossRef]

21. Fazli, M.; Talebi, N. A New Method for Uninterrupted Operation of Wind Turbines Equipped with DFIGs During Grid Faults Using FCL. In Proceedings of the 2010 9th International Conference on Environment and Electrical Engineering, Prague, Czech Republic, 16-19 May 2010. [CrossRef]

22. Rashid, G.; Hasan Ali, M. Bridge-Type Fault Current Limiter for Asymmetric Fault Ride-Through Capacity Enhancement of Doubly Fed Induction Machine Based Wind Generator. In Proceedings of the 2014 IEEE Energy Conversion Congress and Exposition, Pittsburgh, PA, USA, 14-18 September 2014; 14-18 September 2014. [CrossRef]

23. Shen, Y.; Li, C.; Jia, H.; Liu, B.; Li, B.; Coombs, T.A. Investigation on Fault Ride-Through Capability of PMSG-Based Offshore Wind Farm Using the SFCL. IEEE Trans. Appl. Supercond. 2021. [CrossRef]

24. Xie, D.; Xu, Z.; Yang, L.; Østergaard, J.; Xue, Y.; Wong, K.P. A Comprehensive LVRT Control Strategy for DFIG Wind Turbines with Enhanced Reactive Power Support. IEEE Trans. Power Syst. 2013, 28, 3302-3310. [CrossRef]

25. Rahimi, M.; Parniani, M. Efficient Control Scheme of Wind Turbines with Doubly Fed Induction Generators for Low-Voltage Ride-Through Capability Enhancement. IET Renew. Power Gener. 2010, 4, 242-252. [CrossRef]

26. Rahimi, M.; Parniani, M. Coordinated Control Approaches for Low-Voltage Ride-Through Enhancement in Wind Turbines with Doubly Fed Induction Generators. IEEE Trans. Energy Convers. 2010, 25, 873-883. [CrossRef]

27. Sadi, M.A.H.; Ali, M.H. A Fuzzy Logic Controlled Bridge Type Fault Current Limiter for Transient Stability Augmentation of Multi-Machine Power System. IEEE Trans. Power Syst. 2016, 31, 602-611. [CrossRef]

28. Rashid, G.; Ali, M.H. Fault Ride through Capability Improvement of DFIG Based Wind Farm by Fuzzy Logic Controlled Parallel Resonance Fault Current Limiter. Electr. Power Syst. Res. 2017, 146, 1-8. [CrossRef]

29. Li, S.; Wang, J.; Huang, J.; Li, Z.; Jiang, Y.; Zhang, H. Thermal Effect of Short Current of DFIG and Its Impact on Temperature Rise of Rotor Crowbar. Int. Trans. Electr. Energy Syst. 2019, 29, e2825. [CrossRef]

30. O'Sullivan, J.; Rogers, A.; Flynn, D.; Smith, P.; Mullane, A.; O'Malley, M. Studying the Maximum Instantaneous Non-Synchronous Generation in an Island System-Frequency Stability Challenges in Ireland. IEEE Trans. Power Syst. 2014, 29, $2943-2951$. [CrossRef]

31. Behzad, N.S.; Negnevitsky, M. Soft and Fast Starting Induction Motors Using Controllable Resistive Type Fault Current Limiter. In Proceedings of the 2015 IEEE Power \& Energy Society General Meeting, Denver, CO, USA, 26-30 July 2015. [CrossRef]

32. Bhattarai, R.; Gurung, N.; Ghosh, S.; Kamalasadan, S. Parametrically Robust Dynamic Speed Estimation Based Control for Doubly Fed Induction Generator. IEEE Trans. Ind. Appl. 2018, 54, 6529-6542. [CrossRef]

33. Heier, S. Grid Integration of Wind Energy Conversion Systems; Weily: Chichester, UK, 1998.

34. Yuan, H.; Xin, H.; Huang, L.; Wang, Z.; Wu, D. Stability Analysis and Enhancement of Type-4 Wind Turbines Connected to Very Weak Grids under Severe Voltage Sags. IEEE Trans. Energy Convers. 2019, 34, 838-848. [CrossRef] 